\title{
Prototypic Heptamethine Cyanine Incorporating Nanomaterials for Cancer Phototheragnostic
}

\author{
Miguel M. Leitão, Duarte de Melo-Diogo,* Cátia G. Alves, Rita Lima-Sousa, \\ and Ilídio J. Correia*
}

Developing technologies that allow the simultaneous diagnosis and treatment of cancer (theragnostic) has been the quest of numerous interdisciplinary research teams. In this context, nanomaterials incorporating prototypic near infrared (NIR)-light responsive heptamethine cyanines have been showing very promising results for cancer theragnostic. The precisely engineered features of these nanomaterials endow them with the ability to achieve a high tumor accumulation, enabling a tumor's visualization by NIR fluorescence and photoacoustic imaging modalities. Upon interaction with NIR light, the tumor-homed heptamethine cyanine-incorporating nanomaterials can also produce a photothermal/photodynamic effect with a high spatio-temporal resolution and minimal side effects, leading to an improved therapeutic outcome. This progress report analyses the application of nanomaterials incorporating prototypic NIR-light responsive heptamethine cyanines (IR775, IR780, IR783, IR797, IR806, IR808, IR820, IR825, IRDye $800 \mathrm{CW}$, and (ypate) for cancer photothermal therapy, photodynamic therapy, and imaging. Overall, the continuous development of nanomaterials incorporating the prototypic NIR absorbing heptamethine cyanines will cement their phototheragnostic capabilities. physicochemical properties that confer them with the ability to preferentially accumulate within the tumor. ${ }^{[2]}$ Afterward, the tumor zone is externally irradiated with light and the tumor-homed nanomaterials can absorb it. Upon interaction with light, these nanomaterials can produce a temperature increase (photothermal therapy (PTT)) and/or reactive oxygen species (photodynamic therapy (PDT)), which can cause damage toward cancer cells. ${ }^{[3]}$ The use of near infrared (NIR; 750-1000 nm) light to irradiate these nanomaterials is crucial since this type of radiation has minimal/insignificant interactions with the biological components (e.g., proteins, melanin, water). ${ }^{[4,5]}$ In this way, nanomaterials' mediated phototherapies using NIR light can induce a therapeutic effect with high spatial-temporal resolution and minimal side effects. ${ }^{[5-9]}$

These nanostructures can also emit fluorescence upon interaction with the NIR light, enabling their use in NIR fluo-

\section{Introduction}

The development of devices that simultaneously allow the diagnosis and treatment (theragnostic) of cancer has been the focus of different studies performed by worldwide researchers. In this context, light-responsive nanomaterials with theragnostic capabilities have been displaying promising results toward both in vitro and in vivo preclinical cancer models. ${ }^{[1]}$ This therapeutic modality employs nanostructures with well-defined

M. M. Leitão, Dr. D. de Melo-Diogo, C. G. Alves, R. Lima-Sousa,

Dr. I. J. Correia

CICS-UBI-Centro de Investigação em Ciências da Saúde

Universidade da Beira Interior

6200-506 Covilhã, Portugal

E-mail: demelodiogo@fcsaude.ubi.pt; icorreia@ubi.pt

Dr. I. J. Correia

CIEPQPF-Departamento de Engenharia Química

Universidade de Coimbra

Rua Sílvio Lima

3030-790 Coimbra, Portugal

The ORCID identification number(s) for the author(s) of this article can be found under https://doi.org/10.1002/adhm.201901665.

DOI: 10.1002/adhm.201901665 rescence imaging. ${ }^{[7,10]}$ Moreover, the photoinduced heat generated by these nanomaterials can also produce acoustic waves, enabling tissues' visualization through photoacoustic imaging (PAI). ${ }^{11]}$ This cutting-edge modality allows a higher penetration depth and resolution than fluorescence imaging by taking advantage from the acoustic waves' lower scattering in tissues and the high penetration depth of NIR light. ${ }^{[2,11]}$

Among the different nanomaterials used for phototheragnostic applications, those formulated by encapsulating NIR responsive small molecules in nanostructures (e.g., micelles, liposomes, porous nanostructures) have been displaying promising results. ${ }^{[2]}$ In this regard, indocyanine green (ICG) loaded nanomaterials have been by far one of the most studied, since this dye is currently approved by the Food and Drug Administration (FDA) for angiography. Moreover, ICG well as for imaging. ${ }^{[13]}$ Furthermore, ICG loaded nanostructures are also easier to formulate when compared to the inorganic-based phototheragnostic nanoagents. ${ }^{[14]}$ Nevertheless, ICG has a low photostability and a low fluorescence quantum yield. ${ }^{[2,12]}$ Such has motivated the encapsulation of other heptamethine cyanines (e.g., IR780, IR808, IR825) that exhibit improved optical properties in nanostructures for cancer phototheragnostic. ${ }^{[15]}$ loaded nanomaterials can be used for cancer PTT/PDT ${ }^{[9,12]}$ as 
In this progress report, the application of nanomaterials incorporating prototypic NIR responsive heptamethine cyanines for cancer PTT, PDT and imaging is analyzed. Initially, the different NIR responsive heptamethine cyanines are reviewed, emphasizing their optical properties and limitations (Section 2). Afterward, the encapsulation of IR780 (Section 3.1), Cypate (Section 3.2), IR808 (Section 3.3), IR820 (Section 3.4), IR825 (Section 3.5), and other heptamethine cyanines (IR775, IR783, IR797, IR806, IRDye 800CW - Section 3.6) in nanomaterials for cancer phototheragnostic is discussed. Finally, an outlook about the state of the art and the future directions are presented (Section 4). For the sake of brevity, the encapsulation of ICG in nanomaterials will not be analyzed since it has been extensively reviewed elsewhere. ${ }^{[16]}$

\section{Heptamethine Cyanines: Properties and Limitations}

The FDA-approval of ICG has propelled the use of this NIR absorbing small molecule belonging to the heptamethine cyanine family in cancer theragnostic (reviewed in detail in ref. [2])-Figure 1. However, ICG displays critical limitations such as low photostability, rapid blood clearance (within minutes), and inability to specifically target the cancer cells. ${ }^{[12]}$

To bypass these limitations, researchers have been investigating the potential of other prototypic NIR-absorbing heptamethine cyanines for theragnostic applications. When compared to ICG, some of these NIR dyes have improved optical properties, thus displaying enhanced imaging and therapeutic capabilities (Table 1). For instance, IR780 has a higher molar extinction coefficient (265 000-330000 $\mathrm{M}^{-1} \mathrm{~cm}^{-1}$, at $780 \mathrm{~nm})^{[17]}$ than ICG $\left(\begin{array}{llll}115 & 000-204 & 000 \mathrm{M}^{-1} \mathrm{~cm}^{-1} \text {, at }\end{array}\right.$ $785 \mathrm{~nm}),{ }^{[18,19]}$ having an enhanced interaction with NIR light. On the other hand, IR783 has a fluorescence quantum yield of 0.084 , which is slightly greater than that of ICG and other heptamethine cyanines (Table 1). ${ }^{[18]}$ The singlet oxygen quantum yield of IR780 and IR808 is also superior to that of ICG, enabling stronger photodynamic effects. ${ }^{[20]}$ Besides these heptamethine cyanines, IR775, IR797, IR806, IR820, IR825, Cypate, IRDye $800 \mathrm{CW}$, and FD-1080 also have promising optical properties (please see Table 1 for further details). In the particular case of IR780, IR783, and IR808, these have been reported to interact with the organic anionic transporter peptides (OATPs), which are overexpressed by cancer cells, enabling their use for tumor imaging ${ }^{[21-24]}$ (please note that imaging applications require the administration of low doses of the imaging agents (e.g., 0.2-0.3 $\left.\mathrm{mg} \mathrm{kg}^{-1[25,26]}\right)$ ).

Despite their potential, in general, these prototypic NIR absorbing heptamethine cyanines have a poor water solubility, affecting their application for cancer PTT/PDT, in which high doses need to be administered for attaining complete tumor ablation. ${ }^{[27]}$ Furthermore, the hydrophobic character of these dyes may promote their aggregation during circulation, ${ }^{[10]}$ leading to undesirable side effects. In fact, the potential toxicity of these dyes is strongly influenced by their hydrophobicity. For instance, IR780 was shown to induce acute toxicity to healthy mice when administered at a dose of $2 \mathrm{mg} \mathrm{kg}^{-1}$.26] On the other hand, IR808 (which is less hydrophobic due to its

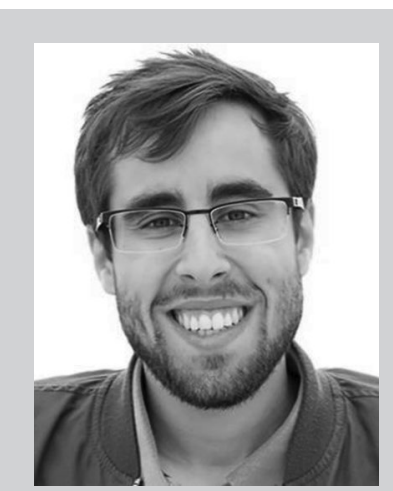

Duarte de Melo-Diogo received his B.Sc. and M.Sc degrees in biomedical sciences from Universidade da Beira Interior in 2012 and 2014 , respectively. In 2018, he concluded his Ph.D. degree in biochemistry from the same university. He is now a researcher at CICS-UBI research center. His research interests are focused on the application of heptamethine cyanine-incorporating nanomaterials and graphene family nanomaterials in cancer phototherapy.

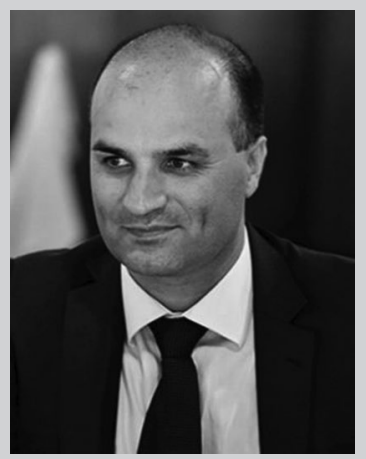

Ilídio J. Correia is an associate professor with habilitation in the Department of Health Sciences at Universidade da Beira Interior. He obtained his B.Sc. and Ph.D. degrees in biochemistry from the University of Lisbon in 1998 and New University of Lisbon in 2003, respectively. His research group is involved in the development of skin and bone substitutes, drug delivery systems, as well as in vitro 3D cell culture models aimed to reproduce solid tumors structural features.

carboxylic groups) did not cause appreciable toxicity in normal mice, when administered at a dose of $150 \mathrm{mg} \mathrm{kg}^{-1}$, throughout 7 days. ${ }^{[25]}$ No adverse effects were observed in normal mice that received a $20 \mathrm{mg} \mathrm{kg}^{-1}$ dose of IRDye $800 \mathrm{CW}$ carboxylate after a 14 days period. ${ }^{[28]}$ Additionally, IR780, IR808, IR820, IR825, and Cypate have been reported to suffer from photodegradation, lowering their potential for continuous tumor monitoring. ${ }^{[29-32]}$

In general, the limitations of these prototypic heptamethine cyanines can be surpassed by encapsulating/incorporating them in nanomaterials. ${ }^{[21,33]}$ In fact, the loading of these agents in the nanomaterials addresses their solubility concerns. ${ }^{[10,33,34]}$ For instance, Pais-Silva et al. verified that by loading IR780 in poly(ethylene glycol) (PEG)-Vitamin E based micelles, the water solubility of the former increased from 0.4 to $46 \mu \mathrm{g} \mathrm{mL}{ }^{-1}{ }^{[35]}$ The safety of these NIR heptamethine cyanines is also greatly enhanced through their incorporation into nanomaterials. ${ }^{[26,36-38]}$ For instance, healthy mice injected with PEG-IR780- $\mathrm{C}_{13}$ micelles, at an IR780 dose of $7 \mathrm{mg} \mathrm{kg}$, did not display toxicity on their major organs nor alterations on the liver- and kidney-function markers after 30 days. ${ }^{[26]}$ The toxicology studies regarding IR825 loaded PEG-poly(maleic anhydride-alt-1-octadecene) (PEG-PMAO) micelles (10 mg kg-1) during 40 days did also not reveal any potential adverse 

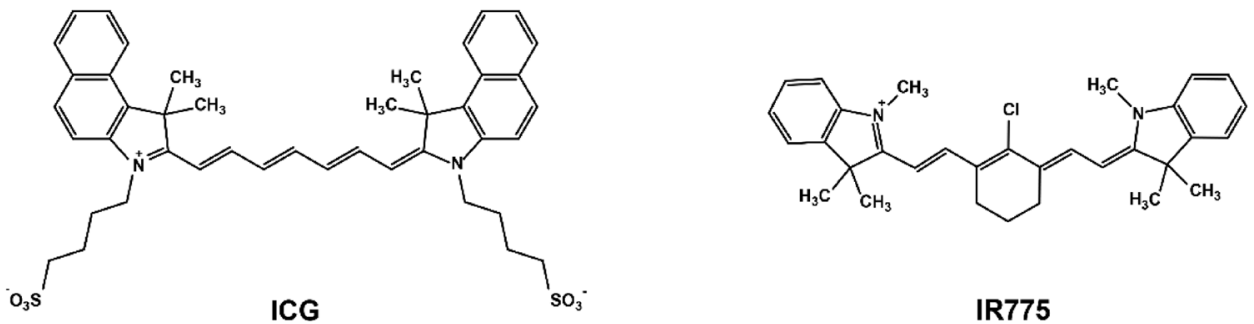

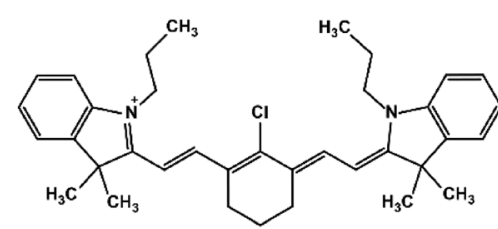

IR780

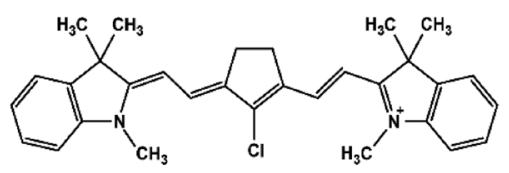

IR797

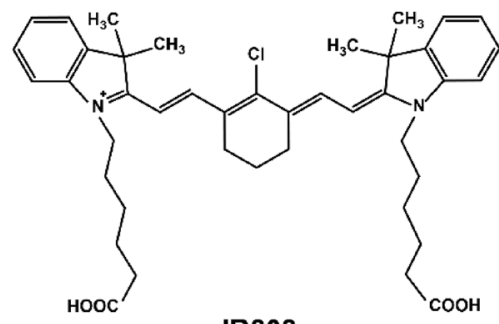

IR808

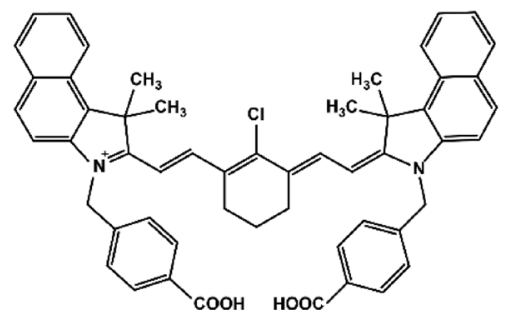

IR825

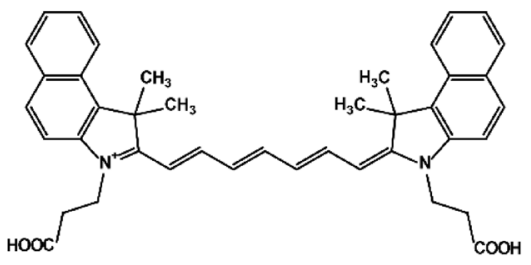

Cypate
IR775

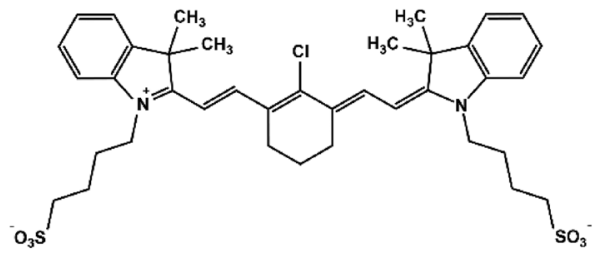

IR783

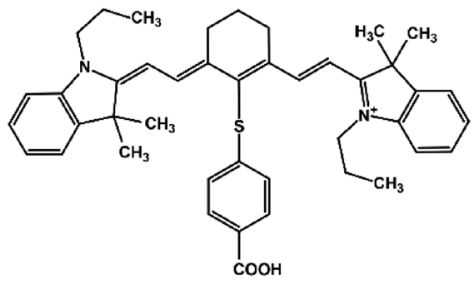

IR806

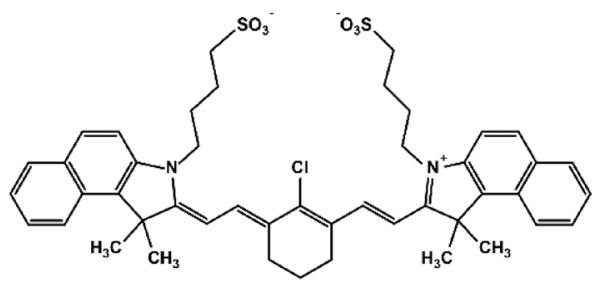

IR820

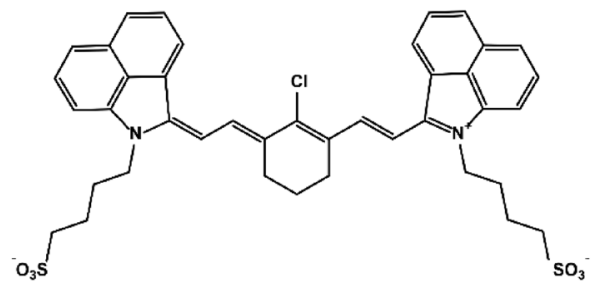

FD-1080

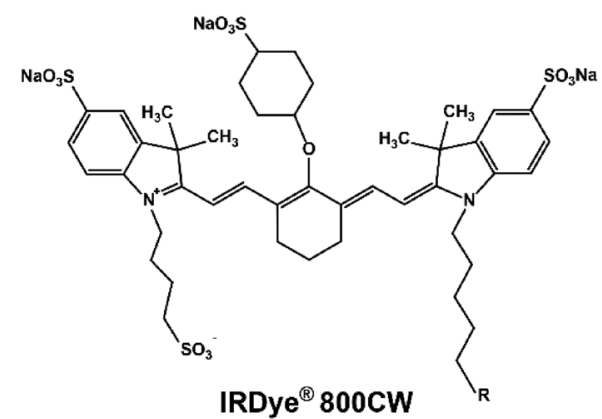

Figure 1. Chemical structure of the prototypic NIR absorbing heptamethine cyanines and of ICG. R: available as IRDye 800CW Carboxylate, NHS ester and maleimide. 
Table 1. Photophysical properties of different agents (including NIR agents) used for cancer related applications. Please note that properties vary according to the experimental conditions reported.

\begin{tabular}{|c|c|c|c|c|c|c|c|}
\hline Name & $\begin{array}{l}\lambda_{\max } \\
{[\mathrm{nm}]}\end{array}$ & $\begin{array}{c}\text { Molar extinction } \\
\text { coefficient }\left[\varepsilon ; \mathrm{M}^{-1} \mathrm{~cm}^{-1}\right]\end{array}$ & $\begin{array}{c}E m_{\max } \\
{[\mathrm{nm}]}\end{array}$ & $\begin{array}{l}\text { Fluorescence quantum } \\
\text { yield }\left[\Phi_{f}\right]\end{array}$ & $\begin{array}{c}\text { Singlet oxygen quantum } \\
\text { yield }\left[\Phi_{\text {so }}\right]\end{array}$ & $\begin{array}{c}\text { Tumor } \\
\text { targeting }\end{array}$ & Ref. \\
\hline Cypate & 785 & 216000 & 822 & 0.065 & 0.02 & - & [18] \\
\hline FD-1080 & $1012-1044$ & $33040-73230$ & 1053-1089 & $0.18-0.44 \%$ & - & - & [75] \\
\hline ICG & $780-785$ & $115000-204000$ & $812-822$ & $0.012-0.078$ & 0.008 & - & {$[18,19]$} \\
\hline IR775 & 768 & $92300^{a)}$ & 790 & $5.1-5.3 \%{ }^{a)}$ & - & - & {$[10,76]$} \\
\hline IR780 & 780 & $265000-330000$ & 798 & 0.07 & 0.127 & Y & {$[17,23,77]$} \\
\hline IR783 & 782 & 261000 & 810 & 0.084 & 0.007 & Y & {$[18,24]$} \\
\hline IR797 & 792 & $444.3^{\text {b) }}$ & 805 & $5.8 \%$ & $0.017^{c)}$ & - & {$[67,76,78]$} \\
\hline IR806 & 806 & $\left.390^{b}\right)$ & $832^{d)}$ & - & - & - & {$[68,79]$} \\
\hline IR808 & $776-783$ & 306000 & $790-816$ & $5.6-5.9 \%$ & 0.036 & Y & {$[20,76,80]$} \\
\hline IR820 & 820 & 202000 & 850 & 0.044 & 0.02 & - & [18] \\
\hline IR825 & 825 & 114500 & - & $<0.1 \%$ & - & - & [39] \\
\hline IRDye 800CW & 774 & $240000-410000$ & 789 & 0.034 & $<0.01$ & - & {$[28,81]$} \\
\hline
\end{tabular}

a) IR775 loaded mPEG-PCL nanoparticles; b) value in $\mathrm{L} \mathrm{g}^{-1} \mathrm{~cm}^{-1}$; c) IR797 modified with acetylacetone; d) approximate value.

effects. ${ }^{[39]}$ Furthermore, the encapsulation of the prototypic heptamethine cyanines in nanostructures can protect them from degradation, leading to an improved photostability. ${ }^{[40,41]}$ For example, Zhang et al. verified that the photothermal capacity of IR825 loaded hollow mesoporous silica nanoparticles is not compromised significantly even after three NIR irradiation cycles. ${ }^{[40]}$ In another study, Xia et al. observed that the photothermal effect mediated by free IR820 decreases drastically after the first cycle of laser irradiation, while IR820 incorporated within porous silicon nanoparticles display almost no loss in their photothermal capacity throughout four irradiation cycles. ${ }^{[41]}$

As importantly, nanomaterials can present a high tumorhoming capacity arising from their ability to extravasate through the tumor leaky vasculature and to take advantage from the dynamic events occurring in the tumor-associated blood vessels. ${ }^{[42]}$ Once on the tumor microenvironment, nanomaterials must penetrate the tumor mass and become internalized in cancer cells. ${ }^{[5]}$ In this regard, nanomaterials functionalized with targeting ligands can achieve a selective uptake by cancer cells by binding to their overexpressed receptors. ${ }^{[34,37,43,44]}$ The ability of the nanomaterials to benefit from these phenomena is dependent on their physicochemical properties (size, surface charge, corona composition, and presence of targeting ligands), which has been reviewed in detail by our and other research groups elsewhere. ${ }^{[5,45]}$

For instance, Pan et al. observed that nonencapsulated IR825- $\mathrm{NH}_{2}$ could not be used for tumor imaging due to its low tumor accumulation. ${ }^{[46]}$ In turn, IR825-polymer conjugate micelles displayed a high tumor uptake, enabling their application for cancer theragnostic. ${ }^{[46]}$ In another work, Song et al. verified that free IR780 and IR780 loaded folic acid (FA)-functionalized PEGylated liposomes present a similar tumor uptake at 1 day post-injection. ${ }^{[4]}$ However, free IR780 was gradually cleared from the tumor zone, emitting minimal fluorescence at the farthest post-injection times. In stark contrast, the IR780 loaded FA-functionalized PEGylated liposomes still remained at the tumor site even after 5 days post-injection. Such enabled continuous tumor monitoring and a photothermal effect that led to tumor eradication. ${ }^{[47]}$

In this way, heptamethine cyanine incorporating nanomaterials can mediate improved cancer phototheragnostic with minimal off-target toxicity (reviewed in Section 3)-Figure 2.

\section{Nanomaterials Incorporating Heptamethine Cyanines for Cancer Phototheragnostic}

\subsection{IR780 Based Nanomaterials}

Nanomaterials encapsulating IR780 have been by far one of the most extensively used in cancer PTT ${ }^{[48]}$ and PDT $^{[49]}$ (see Table 2). Furthermore, these have also been used for cancer NIR imaging ${ }^{[50]}$ and $\mathrm{PAI}^{[49]}$ (see Table 3).

Song et al. produced IR780 loaded FA-functionalized PEG-coated liposomes for cancer theragnostic. ${ }^{[47]}$ The optical properties of this formulation enabled the tracking of its biodistribution by NIR fluorescence imaging. Due to the FA functionalization, these liposomes could achieve an up to 2.5-fold and 5-fold higher tumor accumulation than their nontargeted equivalents (PEGylated liposomes) and free IR780, respectively. Owing to their high tumor-homing capacity, the FA-functionalized PEGylated liposomes incorporating IR780 produced a photoinduced heat up to $50{ }^{\circ} \mathrm{C}$, leading to tumor eradication using an ultralow dosage of the formulation ( $1 \mathrm{mg} \mathrm{kg}^{-1}$ of IR780 equivalents). The PTT/PDT capacity of other IR780 based nanomaterials is summarized in Table 2.

Nanoformulations incorporating IR780 and other therapeutic agents can also be prepared for cancer combinatorial phototherapy (Table 2). ${ }^{[51,52]}$ In this regard, Yang et al. prepared PEGylated micelles incorporating IR780 and doxorubicin (DOX) for application in cancer chemo-PTT. ${ }^{[33]}$ These micelles displayed a $\mathrm{pH}$ - and thermo-responsiveness, presenting an 


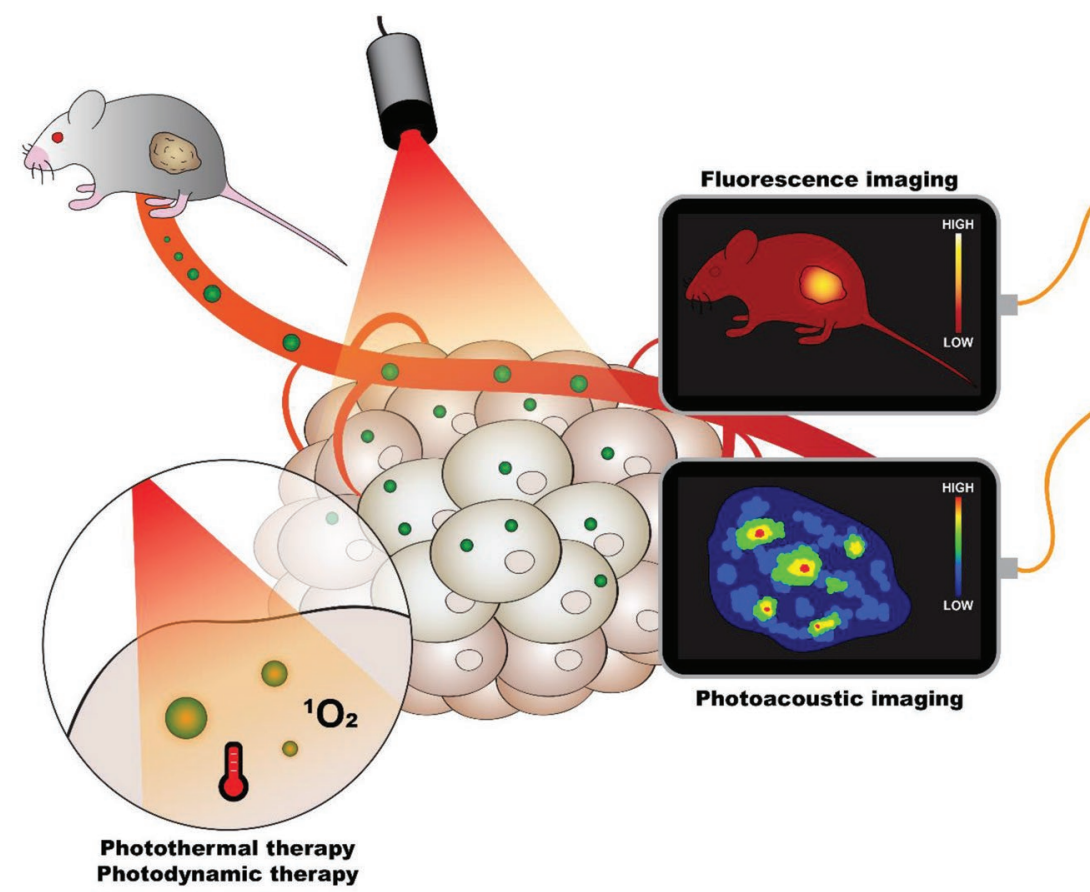

Figure 2. Schematic representation of the phototheragnostic capabilities of the heptamethine cyanine-incorporating nanomaterials.

increased release of the loaded cargo when placed in solutions with an acidic character (i.e., with a $\mathrm{pH}$ similar to that exhibited by the tumor microenvironment) and/or upon NIR laser irradiation. In vivo, this formulation had a high tumorhoming capacity, enabling tumor visualization by NIR fluorescence imaging and PAI-Figure 3 Furthermore, the synergistic chemo-PTT mediated by these micelles led to tumor eradication and inhibition of lung metastasis while the single therapies only led to a reduction of the tumor growth (PTT: IR780 loaded micelles + NIR; chemotherapy: DOX and IR780 loaded micelles).

\subsection{Cypate Based Nanomaterials}

Cypate incorporating nanomaterials have also been used for cancer PTT/PDT ${ }^{[43]}$ (Table 4) as well as for tumor visualization through NIR fluorescence imaging ${ }^{[43]}$ and PAI ${ }^{[54]}$ (Table 3). For this purpose, Cypate (a carboxylated ICG derivative) has been mostly loaded into nanostructures ${ }^{[36,55,56]}$ or conjugated to polymers in order to attain materials capable of assembling into nanostructures. ${ }^{[57,58]}$

In this context, Miao et al. prepared a PEG-Cypate conjugate that was used in the assembly of micelles for application in cancer PTT/PDT and imaging. ${ }^{[57]}$ In vivo, the PEG-Cypate micelles achieved a higher tumor uptake than free Cypate, enabling a superior tumor visualization through NIR fluorescence imaging. Furthermore, the PTT/PDT effect mediated by the PEG-Cypate micelles induced tumors' eradication while only a reduction of tumors' growth was observed for mice treated with free Cypate plus NIR light. Table 4 summarizes the PTT/PDT capacity of other Cypate based nanomaterials.
Cypate based nanostructures incorporating additional therapeutic agents have also been prepared for application in cancer combinatorial phototherapy (Table 4). In this regard, Jia et al. prepared complexes of Melittin (a cytolytic peptide) and Cypate, which were further coated with hyaluronic acid (HA), for application in cancer chemo-PTT. ${ }^{[36]}$ In vivo, the combined chemo-PTT mediated by the HA coated Melittin/Cypate complex nanoagents induced a potent tumor regression and suppressed the occurrence of lung metastasis. In contrast, mice treated with the single therapies only experienced a reduction in their tumors' growth and displayed metastasis in the lungs (PTT: free Cypate + NIR light; chemotherapy: HA coated Melittin/ Cypate complex nanoagents without NIR irradiation).

\subsection{IR808 Based Nanomaterials}

Nanomaterials incorporating IR808 (also known as MHI-148) have also been showing promising properties for cancer PTT/PDT as well as for the visualization of tumors through NIR fluorescence imaging and PAI ${ }^{[21,30]}$ (Tables 5 and 3). For this purpose, IR808 (a carboxylated heptamethine cyanine) has been covalently conjugated to polymeric backbones, which are subsequently used in the preparation of IR808 based nanoparticles. ${ }^{[21,30,37]}$

In this context, Li et al. prepared IR808-HA conjugate nanoparticles, which displayed a higher internalization by cancer cells due to their ability to target the CD44 receptors that are overexpressed by cancer cells. ${ }^{[30]}$ In vivo, the maximum tumor uptake of free IR808 occurred at $12 \mathrm{~h}$ post-injection, decreasing rapidly afterward. In contrast, the IR808-HA nanoparticles achieved their highest tumor accumulation at $24 \mathrm{~h}$ post-injection and remained at the tumor site for at least $96 \mathrm{~h}$. Due to these facts, the IR808-HA nanoparticles enabled the visualization of the tumors by NIR fluorescence imaging during $96 \mathrm{~h}$ (and by PAI for at least $48 \mathrm{~h}$ ). Furthermore, owing to their high tumor uptake, the PTT mediated by the IR808HA nanoparticles induced tumor eradication while the PTT mediated by free IR808 only led to a reduction of the tumor growth.

In another work, IR808 was conjugated to the primary amine groups of poly(ethylenimine) (PEI)-PEG-graphene oxide (GO), leading to the assembly of nanostructures with photodynamic potential (conferred by IR808) and enhanced photothermal capacity (conferred by IR808 and GO). ${ }^{[21]}$ The NIR imaging of the tumor bearing mice revealed the ability of these nanomaterials to accumulate at the tumor site. Afterward, the tumor zone was irradiated and the PTT/PDT mediated by the IR808GO nanomaterials induced complete tumor ablation-Figure 4. In contrast, the PTT/PDT mediated by free IR808 only induced a reduction of the tumor growth, which can be explained by its weaker photothermal effect. 
Table 2. In vivo therapeutic performance of IR780 based nanostructures.

\begin{tabular}{|c|c|c|c|c|c|c|c|c|}
\hline $\begin{array}{l}\text { IR780 based } \\
\text { nanostructures }\end{array}$ & $\begin{array}{l}\text { Phototherapy } \\
\text { modality }\end{array}$ & Tumor model & $\begin{array}{l}\text { Administration } \\
\text { route }\end{array}$ & Dose $^{\text {a) }}$ & Laser parameters & $\begin{array}{l}\text { Other therapeutic } \\
\text { molecules }\end{array}$ & $\begin{array}{c}\text { Therapeutic } \\
\text { effect }\end{array}$ & Ref. \\
\hline $\begin{array}{l}\text { IR780 and DOX loaded } \\
\text { liposomes }\end{array}$ & PTT & $\begin{array}{l}4 \mathrm{~T} 1 \text { tumor bearing } \\
\text { mice }\end{array}$ & $\begin{array}{l}\text { intratumoral } \\
\text { (i.t.) }\end{array}$ & $20 \mu \mathrm{g}$ & $\begin{array}{c}808 \mathrm{~nm} ; 1.0 \mathrm{~W} \mathrm{~cm}^{-2} \\
5 \mathrm{~min}\end{array}$ & DOX & $\begin{array}{c}\text { Tumor } \\
\text { eradication }\end{array}$ & [6] \\
\hline $\begin{array}{l}\text { IR780 and } \mathrm{Ce}^{\mathrm{c}} \text { l loaded } \\
\mathrm{HSA}^{\mathrm{d})} \text { nanoparticles }\end{array}$ & $\mathrm{PTT} / \mathrm{PDT}$ & $\begin{array}{l}\text { CT-26 tumor bearing } \\
\text { mice }\end{array}$ & $\begin{array}{l}\text { intravenous } \\
\text { (i.v.) }\end{array}$ & $\begin{array}{l}0.4 \mathrm{mg} \mathrm{kg}^{-1} \\
\text { of Ce6 }\end{array}$ & $\begin{array}{c}660 \mathrm{~nm} ; 0.04 \mathrm{~W} \mathrm{~cm}^{-2} \\
15 \mathrm{~min} \\
808 \mathrm{~nm} ; \\
0.533 \mathrm{~W} \mathrm{~cm}^{-2} ; 40 \mathrm{~s}\end{array}$ & Ce6 & $\begin{array}{c}\text { Tumor } \\
\text { eradication }\end{array}$ & [82] \\
\hline $\begin{array}{l}\text { IR780 loaded FA func- } \\
\text { tionalized PEGylated } \\
\text { liposomes }\end{array}$ & PTT & $\begin{array}{l}\text { SKOV-3 tumor } \\
\text { bearing mice }\end{array}$ & i.v. & $1 \mathrm{mg} \mathrm{kg}^{-1}$ & $\begin{array}{c}808 \mathrm{~nm} ; 1.0 \mathrm{~W} \mathrm{~cm}^{-2} \\
10 \mathrm{~min}\end{array}$ & - & $\begin{array}{c}\text { Tumor } \\
\text { eradication }\end{array}$ & [47] \\
\hline $\begin{array}{l}\text { IR780 loaded HA func- } \\
\text { tionalized micelles }{ }^{f} \text { ) }\end{array}$ & $\mathrm{PTT} / \mathrm{PDT}$ & $\begin{array}{l}\text { MDA-MB-231 tumor } \\
\text { bearing mice }\end{array}$ & i.v. & $1.4 \mathrm{mg} \mathrm{kg}^{-1}$ & $\begin{array}{c}808 \mathrm{~nm} ; 0.8 \mathrm{~W} \mathrm{~cm}^{-2} \\
10 \mathrm{~min}\end{array}$ & - & $\begin{array}{c}\text { Tumor } \\
\text { eradication }\end{array}$ & [83] \\
\hline $\begin{array}{l}\text { IR780 and DOX loaded } \\
\text { PEGylated micellesg) }\end{array}$ & PTT & $\begin{array}{l}4 \mathrm{~T} 1 \text { tumor bearing } \\
\text { mice }\end{array}$ & i.v. & $\begin{array}{l}0.5 \mathrm{mg} \mathrm{kg}^{-1} \\
(3 \text { times) }\end{array}$ & $\begin{array}{c}808 \mathrm{~nm} ; 1.0 \mathrm{~W} \mathrm{~cm}^{-2} \\
5 \mathrm{~min} \\
(3 \text { times })\end{array}$ & DOX & $\begin{array}{c}\text { Tumor } \\
\text { eradication }\end{array}$ & [53] \\
\hline $\begin{array}{l}\text { IR780 loaded FA-Gra- } \\
\text { phene quantum dots }\end{array}$ & PTT & $\begin{array}{l}\text { HeLa tumor bearing } \\
\text { mice }\end{array}$ & i.v. & $\begin{array}{c}2 \mathrm{mg} \mathrm{kg}^{-1} \text { of } \\
\text { nanostructures }\end{array}$ & $\begin{array}{c}808 \mathrm{~nm} ; 1.0 \mathrm{~W} \mathrm{~cm}^{-2} \\
5 \mathrm{~min}\end{array}$ & - & $\begin{array}{c}\text { Tumor } \\
\text { eradication }\end{array}$ & [84] \\
\hline $\begin{array}{l}\mathrm{RBC} \text { h) membrane-coated } \\
\text { IR780 and DTX') } \\
\text { loaded PCL-PEG-PCL } \\
\text { nanoparticles }\end{array}$ & $\mathrm{PTT} / \mathrm{PDT}$ & $\begin{array}{c}\text { MCF-7 tumor bearing } \\
\text { mice }\end{array}$ & i.v. & $\begin{array}{l}1.67 \mathrm{mg} \mathrm{kg}^{-1} \\
(3 \text { times })\end{array}$ & $\begin{array}{c}808 \mathrm{~nm} ; 1.5 \mathrm{~W} \mathrm{~cm}^{-2} \\
5 \mathrm{~min}\end{array}$ & DTX & $\begin{array}{c}\text { Tumor } \\
\text { eradication }\end{array}$ & [49] \\
\hline $\begin{array}{l}\text { IR780 and AMD3100 } \\
\text { loaded liposomesi) }\end{array}$ & PTT & $\begin{array}{l}4 \mathrm{~T} 1 / \text { Luc tumor } \\
\text { bearing mice }\end{array}$ & i.v. & $\begin{array}{l}1.4 \mathrm{mg} \mathrm{kg}^{-1} \\
(8 \text { times) }\end{array}$ & $\begin{array}{c}808 \mathrm{~nm} ; 1.0 \mathrm{~W} \mathrm{~cm}^{-2} \\
4 \mathrm{~min}\end{array}$ & AMD3100 & $\begin{array}{c}\text { Tumor } \\
\text { eradication }\end{array}$ & [85] \\
\hline $\begin{array}{l}\text { IR780 loaded CXCR4- } \\
\text { targeted liposomesk }\end{array}$ & PTT & $\begin{array}{l}4 \mathrm{Tl} / \text { Luc tumor } \\
\text { bearing mice }\end{array}$ & i.v. & $\begin{array}{l}1.4 \mathrm{mg} \mathrm{kg}^{-1} \\
(8 \text { times) }\end{array}$ & $\begin{array}{c}808 \mathrm{~nm} ; 1.0 \mathrm{~W} \mathrm{~cm}^{-2} \\
5 \mathrm{~min}\end{array}$ & AMD3100 & $\begin{array}{c}\text { Tumor } \\
\text { eradication }\end{array}$ & [86] \\
\hline $\begin{array}{l}\text { IR780 loaded FA func- } \\
\text { tionalized PEGylated } \\
\text { liposomes') }\end{array}$ & PTT & $\begin{array}{l}\text { U87 tumor bearing } \\
\text { mice }\end{array}$ & i.v. & $10 \mu \mathrm{g}$ & $\begin{array}{c}808 \mathrm{~nm} ; 1.0 \mathrm{~W} \mathrm{~cm}^{-2} \\
2 \mathrm{~min}\end{array}$ & - & $\begin{array}{l}\text { Tumor } \\
\text { regression }\end{array}$ & [87] \\
\hline $\begin{array}{l}\text { IR780 and DOX loaded } \\
\text { PEGylated micelles }{ }^{m} \text { ) }\end{array}$ & PTT & $\begin{array}{l}\text { MCF-7/DOX tumor } \\
\text { bearing mice }\end{array}$ & i.v. & $\begin{array}{l}20 \mu \mathrm{g} \\
\text { (twice) }\end{array}$ & $\begin{array}{c}808 \mathrm{~nm} ; 4.0 \mathrm{~W} \mathrm{~cm}^{-2} \\
5 \mathrm{~min} \\
\text { (twice) }\end{array}$ & DOX & $\begin{array}{l}\text { Tumor } \\
\text { regression }\end{array}$ & [88] \\
\hline $\begin{array}{l}\mathrm{RV}^{\mathrm{n})} \text { loaded IR780-BSA }{ }^{\circ} \text {. } \\
\mathrm{TiS}_{2} \text { nanosheets }\end{array}$ & PTT & $\begin{array}{l}\text { CT-26 tumor bearing } \\
\text { mice }\end{array}$ & i.v. & $0.5 \mathrm{mg} \mathrm{kg}^{-1}$ & $\begin{array}{c}808 \mathrm{~nm} ; 0.3 \mathrm{~W} \mathrm{~cm}^{-2} \\
3 \mathrm{~min}\end{array}$ & $\begin{array}{l}\mathrm{RV} \\
\mathrm{TiS}_{2}\end{array}$ & $\begin{array}{l}\text { Tumor } \\
\text { regression }\end{array}$ & [48] \\
\hline $\begin{array}{l}\text { IR780 loaded iRGDP). } \\
\text { functionalized Dextran- } \\
\text { poly(lysine)-based } \\
\text { nanostructures incorpo- } \\
\text { rating fluorocarbons }\end{array}$ & PDT & $\begin{array}{l}4 \mathrm{~T} 1 \text { tumor bearing } \\
\text { mice }\end{array}$ & i.v. & $0.5 \mathrm{mg} \mathrm{kg}^{-1}$ & $\begin{array}{c}808 \mathrm{~nm} ; 2.0 \mathrm{~W} \mathrm{~cm}^{-2} \\
5 \mathrm{~min}\end{array}$ & Fluorocarbons & $\begin{array}{l}\text { Tumor } \\
\text { regression }\end{array}$ & [89] \\
\hline $\begin{array}{l}\text { IR780 and SPION9) } \\
\text { loaded PEGylated HSA } \\
\text { nanoparticles }\end{array}$ & PTT & $\begin{array}{l}\text { CT-26 tumor bearing } \\
\text { mice }\end{array}$ & i.v. & $1 \mathrm{mg} \mathrm{kg}^{-1}$ & $\begin{array}{c}808 \mathrm{~nm} ; 1.0 \mathrm{~W} \mathrm{~cm}^{-2} \\
5 \mathrm{~min}\end{array}$ & SPION & $\begin{array}{l}\text { Tumor } \\
\text { regression }\end{array}$ & [90] \\
\hline $\begin{array}{l}\text { IR780 and Ce6 loaded } \\
\text { TPP-functionalized } \\
\text { PEGylated liposomes }\end{array}$ & $\mathrm{PTT} / \mathrm{PDT}$ & $\begin{array}{l}\text { HeLa tumor bearing } \\
\text { mice }\end{array}$ & i.v. & $\begin{array}{l}1.5 \mathrm{mg} \mathrm{kg}^{-1} \\
\text { (twice) }\end{array}$ & $\begin{array}{c}660 \mathrm{~nm} ; 0.5 \mathrm{~W} \mathrm{~cm}^{-2} \\
5 \mathrm{~min} \\
808 \mathrm{~nm} ; 1.0 \mathrm{~W} \mathrm{~cm}^{-2} \\
5 \mathrm{~min} \\
\text { (twice) }\end{array}$ & $\mathrm{Ce} 6$ & $\begin{array}{l}\text { Tumor } \\
\text { regression }\end{array}$ & [51] \\
\hline $\begin{array}{l}\text { IR780 and DTX loaded } \\
\text { HSA nanoparticles }\end{array}$ & $\mathrm{PTT} / \mathrm{PDT}$ & $\begin{array}{l}\text { 22RV1 tumor bearing } \\
\text { mice }\end{array}$ & i.v. & $5 \mathrm{mg} \mathrm{kg}^{-1}$ & $\begin{array}{c}808 \mathrm{~nm} ; 1.0 \mathrm{~W} \mathrm{~cm}^{-2} \\
4 \mathrm{~min}\end{array}$ & DTX & $\begin{array}{l}\text { Tumor } \\
\text { regression }\end{array}$ & [91] \\
\hline $\begin{array}{l}\text { IR780 and DOX loaded } \\
\text { PEGylated liposomes }\end{array}$ & PTT & $\begin{array}{l}\text { KB tumor bearing } \\
\text { mice }\end{array}$ & i.v. & $10 \mathrm{mg} \mathrm{kg}^{-1}$ of DOX & $\begin{array}{c}780 \mathrm{~nm} ; 1.0 \mathrm{~W} \mathrm{~cm}^{-2} \\
15 \mathrm{~min}\end{array}$ & DOX & $\begin{array}{l}\text { Tumor } \\
\text { regression }\end{array}$ & [92] \\
\hline $\begin{array}{l}\text { IR780 and DOX } \\
\text { loaded PDA } \\
\text { TPGS -coated } \\
\text { TPI)-micelles }\end{array}$ & PTT/PDT & $\begin{array}{l}\text { MCF-7/ADR tumor } \\
\text { bearing mice }\end{array}$ & i.v. & $\begin{array}{l}3 \mathrm{mg} \mathrm{kg}^{-1} \text { of DOX } \\
\quad(10 \text { times })\end{array}$ & $\begin{array}{c}808 \mathrm{~nm} ; 0.5 \mathrm{~W} \mathrm{~cm}^{-1} \\
5 \mathrm{~min} \\
(20 \text { times })\end{array}$ & $\begin{array}{l}\text { PDA } \\
\text { DOX }\end{array}$ & $\begin{array}{l}\text { Tumor } \\
\text { regression }\end{array}$ & [93] \\
\hline PEG-IR780- $\mathrm{C}_{13}$ micelles & PTT & $\begin{array}{l}\text { RENCA tumor } \\
\text { bearing mice }\end{array}$ & i.v. & $\begin{array}{c}40 \mathrm{mg} \mathrm{kg}^{-1} \text { of } \\
\text { nanostructures }\end{array}$ & $\begin{array}{c}808 \mathrm{~nm} ; 0.8 \mathrm{~W} \mathrm{~cm}^{-2} \\
10 \mathrm{~min}\end{array}$ & - & $\begin{array}{l}\text { Tumor } \\
\text { regression }\end{array}$ & [94] \\
\hline
\end{tabular}


Table 2. Continued.

\begin{tabular}{|c|c|c|c|c|c|c|c|c|}
\hline $\begin{array}{l}\text { IR780 based } \\
\text { nanostructures }\end{array}$ & $\begin{array}{l}\text { Phototherapy } \\
\text { modality }\end{array}$ & Tumor model & $\begin{array}{l}\text { Administration } \\
\text { route }\end{array}$ & Dose $^{\text {a) }}$ & Laser parameters & $\begin{array}{c}\text { Other therapeutic } \\
\text { molecules }\end{array}$ & $\begin{array}{c}\text { Therapeutic } \\
\text { effect }\end{array}$ & Ref. \\
\hline $\begin{array}{l}\text { IR780 and Perfluoro- } \\
\text { pentane loaded CRCD- } \\
\text { functionalized PEGylated } \\
\text { nanoparticles }\end{array}$ & PTT & $\begin{array}{l}\text { B16 tumor bearing } \\
\text { mice }\end{array}$ & i.v. & $\begin{array}{c}1 \mathrm{mg} \text { of } \\
\text { nanostructures }\end{array}$ & $\begin{array}{c}808 \mathrm{~nm} ; 2.0 \mathrm{~W} \mathrm{~cm}^{-2} \\
5 \mathrm{~min}\end{array}$ & Perfluoropentane & $\begin{array}{l}\text { Tumor growth } \\
\text { inhibition }\end{array}$ & [38] \\
\hline $\begin{array}{l}\text { IR780 and Cabazitaxel } \\
\text { loaded PEGylated } \\
\text { micelles }{ }^{\mathrm{w})}\end{array}$ & РTT & $\begin{array}{l}4 \mathrm{~T} 1 \text { tumor bearing } \\
\text { mice }\end{array}$ & i.v. & $5 \mathrm{mg} \mathrm{kg}^{-1}$ & $\begin{array}{c}808 \mathrm{~nm} ; 0.5 \mathrm{~W} \mathrm{~cm}^{-2} \\
5 \mathrm{~min}\end{array}$ & Cabazitaxel & $\begin{array}{c}\text { Tumor growth } \\
\text { inhibition }\end{array}$ & [95] \\
\hline 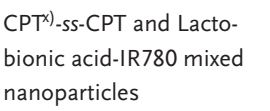 & PTT & $\begin{array}{l}\text { Hep1-6 tumor } \\
\text { bearing mice }\end{array}$ & i.v. & $\begin{array}{c}5.74 \mu \mathrm{mol} \mathrm{kg}{ }^{-1} \text { of } \\
\text { nanostructures }\end{array}$ & $\begin{array}{c}660 \mathrm{~nm} ; 1.0 \mathrm{~W} \mathrm{~cm}^{-2} \\
5 \mathrm{~min}\end{array}$ & CPT & $\begin{array}{l}\text { Tumor growth } \\
\text { inhibition }\end{array}$ & [96] \\
\hline $\begin{array}{l}\text { IR780 loaded transferrin } \\
\text { nanoparticles }\end{array}$ & $\mathrm{PTT} / \mathrm{PDT}$ & $\begin{array}{l}\text { CT-26 tumor bearing } \\
\text { mice }\end{array}$ & i.v. & $20 \mathrm{mg} \mathrm{kg}^{-1}$ & $\begin{array}{c}808 \mathrm{~nm} ; 1.0 \mathrm{~W} \mathrm{~cm}^{-2} \\
5 \mathrm{~min}\end{array}$ & - & $\begin{array}{l}\text { Tumor growth } \\
\text { inhibition }\end{array}$ & [97] \\
\hline $\begin{array}{l}\text { (R780 and PFOBY) } \\
\text { loaded } \\
\text { cRGDK functionalized } \\
\text { PEG-PCL micelles }\end{array}$ & PDT & $\begin{array}{l}\text { MDA-MB-231 tumor } \\
\text { bearing mice }\end{array}$ & i.v. & $20 \mu \mathrm{g}$ & $\begin{array}{c}808 \mathrm{~nm} ; 2.0 \mathrm{~W} \mathrm{~cm}^{-2} \\
20 \mathrm{~s}\end{array}$ & PFOB & $\begin{array}{l}\text { Tumor growth } \\
\text { reduction }\end{array}$ & [98] \\
\hline $\begin{array}{l}\text { IR780 and PFOB loaded } \\
\text { PEG-PLGA nanoparticles }\end{array}$ & PTT/PDT & $\begin{array}{l}\text { A549 tumor bearing } \\
\text { mice }\end{array}$ & i.t. & $20 \mu \mathrm{g}$ & $\begin{array}{c}808 \mathrm{~nm} ; 2.0 \mathrm{~W} \mathrm{~cm}^{-2} \\
1 \mathrm{~min}\end{array}$ & PFOB & $\begin{array}{l}\text { Tumor growth } \\
\text { reduction }\end{array}$ & [99] \\
\hline $\begin{array}{l}\text { IR780 and PTX) loaded } \\
\text { isopentyl nitrite-HSA } \\
\text { nanoparticles }\end{array}$ & $\mathrm{PTT} / \mathrm{PDT}$ & $\begin{array}{l}4 \mathrm{Tl} \text { tumor bearing } \\
\text { mice }\end{array}$ & i.v. & $40 \mu \mathrm{g}$ & $\begin{array}{c}808 \mathrm{~nm} ; 0.8 \mathrm{~W} \mathrm{~cm}^{-2} \\
45 \mathrm{~s} \\
\text { (twice) }\end{array}$ & $\begin{array}{c}\text { PTX } \\
\text { Nitric oxide }\end{array}$ & $\begin{array}{l}\text { Tumor growth } \\
\text { reduction }\end{array}$ & [100] \\
\hline $\begin{array}{l}\text { IR780 loaded PEGylated } \\
\text { micelles }^{\text {aa) }}\end{array}$ & PTT & $\begin{array}{c}\text { MCF-7 tumor bearing } \\
\text { mice }\end{array}$ & i.v. & $4 \mathrm{mg} \mathrm{kg}^{-1}$ & $\begin{array}{c}808 \mathrm{~nm} ; 1.6 \mathrm{~W} \mathrm{~cm}^{-2} \\
5 \mathrm{~min}\end{array}$ & - & $\begin{array}{l}\text { Tumor growth } \\
\text { reduction }\end{array}$ & [101] \\
\hline $\begin{array}{l}\text { DOX loaded } \\
\text { IR780-micelles } \\
\text { ab) }\end{array}$ & PTT/PDT & $\begin{array}{c}\text { MCF-7 tumor bearing } \\
\text { mice }\end{array}$ & i.v. & $\begin{array}{l}0.5 \mathrm{mg} \mathrm{kg}^{-1} \\
(10 \text { times })\end{array}$ & $\begin{array}{c}808 \mathrm{~nm} ; 0.5 \mathrm{~W} \mathrm{~cm}^{-2} \\
3 \mathrm{~min} \\
(10 \text { times })\end{array}$ & DOX & $\begin{array}{l}\text { Tumor growth } \\
\text { reduction }\end{array}$ & [102] \\
\hline $\begin{array}{l}\text { DOX loaded PEG-IR780- } \\
C_{13} \text {-based liposomes }{ }^{\mathrm{ac})}\end{array}$ & PTT & $\begin{array}{l}\text { CT-26 tumor bearing } \\
\text { mice }\end{array}$ & i.v. & $\begin{array}{l}6.2 \mathrm{mg} \mathrm{kg}^{-1} \text { of } \\
\text { PEG-IR780- } \mathrm{C}_{13}\end{array}$ & $\begin{array}{c}808 \mathrm{~nm} ; 1.0 \mathrm{~W} \mathrm{~cm}^{-2} \\
3 \mathrm{~min}\end{array}$ & DOX & $\begin{array}{l}\text { Tumor growth } \\
\text { reduction }\end{array}$ & [103] \\
\hline $\begin{array}{l}\text { Sunitinib and IR780 } \\
\text { loaded liposomes }\end{array}$ & PTT & $\begin{array}{l}4 \mathrm{~T} 1 \text { tumor bearing } \\
\text { mice }\end{array}$ & i.v. & $\begin{array}{l}1 \mathrm{mg} \mathrm{kg}^{-1} \\
\text { (8 times) }\end{array}$ & $\begin{array}{c}808 \mathrm{~nm} ; 1.0 \mathrm{~W} \mathrm{~cm}^{-2} \\
4 \mathrm{~min} \\
\text { (8 times) }\end{array}$ & Sunitinib & $\begin{array}{l}\text { Tumor growth } \\
\text { reduction }\end{array}$ & {$[52]$} \\
\hline $\begin{array}{l}\text { IR780 loaded lipid } \\
\text { nanocarriers }\end{array}$ & PTT & $\begin{array}{l}\text { CT-26 tumor bearing } \\
\text { mice }\end{array}$ & via oral gavage & $\begin{array}{l}6.5 \mathrm{mg} \mathrm{kg}^{-1} \\
\text { (twice) }\end{array}$ & $\begin{array}{c}808 \mathrm{~nm} ; 2.0 \mathrm{~W} \mathrm{~cm}^{-2} \\
1 \mathrm{~min}\end{array}$ & - & $\begin{array}{l}\text { Tumor growth } \\
\text { reduction }\end{array}$ & [104] \\
\hline $\begin{array}{l}\text { IR780 loaded } \mathrm{Hb}^{\text {af) }} \\
\text { nanoparticles }\end{array}$ & РTT & $\begin{array}{l}\text { CT-26 tumor bearing } \\
\text { mice }\end{array}$ & via oral gavage & $\begin{array}{l}6.5 \mathrm{mg} \mathrm{kg}^{-1} \\
\text { (twice) }\end{array}$ & $\begin{array}{c}808 \mathrm{~nm} ; 2.0 \mathrm{~W} \mathrm{~cm}^{-2} \\
1 \mathrm{~min} \\
\text { (twice) }\end{array}$ & - & $\begin{array}{l}\text { Tumor growth } \\
\text { reduction }\end{array}$ & [105] \\
\hline $\begin{array}{l}\text { IR780 loaded PEGylated } \\
\text { liposomesag) }\end{array}$ & PTT & $\begin{array}{l}\text { 4T1/Luc tumor } \\
\text { bearing mice }\end{array}$ & i.v. & $\begin{array}{l}25 \mathrm{mg} \mathrm{kg}^{-1} \text { of } \\
\text { nanostructures }\end{array}$ & $\begin{array}{c}808 \mathrm{~nm} ; 1.0 \mathrm{~W} \mathrm{~cm}^{-2} \\
10 \mathrm{~min}\end{array}$ & - & $\begin{array}{l}\text { Tumor growth } \\
\text { reduction }\end{array}$ & [106] \\
\hline
\end{tabular}

a) Dose of heptamethine cyanine (unless stated otherwise); b)formulated using 1,2-dipalmitoyl-sn-glycero-3-phospholcholine (DPPC), 1-myristoyl-2-palmitoyl-sn-glycero3-phosphocholine, and 1,2-distearoyl-sn-glycero-3-phosphoethanolamine- $N$-[methoxy (polyethylene glycol)] (DSPE-PEG); ${ }^{c}$ chlorin e6; ${ }^{\text {d) }}$ human serum albumin; ${ }^{\text {e) }}$ formulated with DPPC, cholesterol, DSPE-PEG-Folate; ${ }^{\mathrm{f}}$ formulated with an HA-cholesterol conjugate; g) formulated using PEG-poly (acrylamide-co-acrylonitrile-co-vinylimidazole); ${ }^{\text {h) }}$ red blood cells; i) docetaxel; i) prepared using soybean phospholipids, trilaurin, cholesterol and sodium dodecyl sulfate; ${ }^{k}$ formulated with phosphatidylcholine, medium chain triglycerides, trilaurin and AMD3100; I)formulated with DPPC, DSPE-PEG-FA; m)formulated with PEG-poly ( $N$-acryloylglycinamide-co-acrylonitrile); ${ }^{n)}$ resveratrol; ${ }^{\circ}$ )bovine serum albumin; P) tripeptide arginine-glycine-aspartic-acid; a) superparamagnetic iron oxide nanoparticles; r) formulated with DPPC, Cholesterol, DSPE-PEC and DSPEPEG-Triphenylphosphonium (TPP); s) formulated with DPPC, cholesterol, DSPE-PEG and DSPE-PEG-FA; ${ }^{\text {t) }}$ polydopamine; ${ }^{\text {u) }}$ d- $\alpha$-tocopheryl poly (ethylene glycol) 1000 succinate; v)cyclic RGD (cRGD) functionalized PLGA-PEG-based nanoparticles; w) formulated with PEG-b-poly(acrylamide-co-acrylonitrile); ${ }^{x}$ camptothecin; y)perfluorooctyl

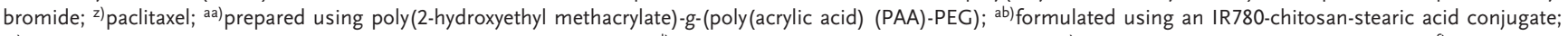
ac) formulated using lecithin, cholesterol and PEG-IR780- $\mathrm{C}_{13}$ conjugate; ${ }^{\text {ad) }}$ formulated using soybean phospholipids; ${ }^{\text {ae) }}$ soy lecithin, trilaurin and Labrafac $\mathrm{CC}$; ${ }^{\text {af) }}$ hemoglobin; ag) formulated with DPPC, cholesterol and DSPE-PEC.

\subsection{IR820 Based Nanomaterials}

The application of nanoparticles incorporating IR820 in cancer PTT/PDT and NIR imaging and PAI has also been extensively investigated (Tables 6 and 3). ${ }^{[59-61]}$ For instance,
Huang et al. incorporated IR820 in ferritin nanocages, demonstrating the ability of these nanostructures to accumulate at the tumor and image it through PAI. ${ }^{[60]}$ Upon NIR laser irradiation, these nanostructures induced a temperature increase of about $24^{\circ} \mathrm{C}$, leading to complete tumor eradication. 
Table 3. Application of heptamethine cyanine based nanostructures for in vivo NIR tumor imaging.

\begin{tabular}{|c|c|c|c|c|c|c|}
\hline Heptamethine cyanine based nanostructures & Tumor model & Administration route & Dose $^{a)}$ & PAI & $\begin{array}{l}\text { NIR fluorescence } \\
\text { imaging }\end{array}$ & Ref. \\
\hline IR780 and DOX loaded liposomesc) & $4 \mathrm{Tl}$ tumor bearing mice & i.t. & non disclosed (N.D.) & - & $\mathrm{Y}$ & [6] \\
\hline IR780 and DOX loaded PEGylated liposomes ${ }^{\mathrm{d})}$ & KB tumor bearing mice & i.v. & N.D. & - & Y & [92] \\
\hline $\begin{array}{l}\text { IR780 loaded FA functionalized PEGylated } \\
\text { liposomes }\end{array}$ & U87 tumor bearing mice & i.v. & N.D. & - & Y & [87] \\
\hline $\begin{array}{l}\text { IR780 loaded V7-fuctionalized chitosan coated } \\
\text { mesoporous silica nanoparticles }\end{array}$ & ES-2 or A2780 tumor bearing mice & i.v. & $0.05 \mathrm{nmol}$ & Y & - & [107] \\
\hline IR780 loaded PECylated liposomese) & U87M2/Luc tumor bearing mice & i.v. & $2 \mathrm{nmol}$ & - & Y & [108] \\
\hline $\begin{array}{l}\text { IR780 and PFOB loaded } \\
\text { CRGDK functionalized PEG-PCL micelles }\end{array}$ & MDA-MB-231 tumor bearing mice & i.v. & $20 \mu \mathrm{g}$ & Y & Y & [98] \\
\hline IR780 loaded Pluronic F-127 nanoparticles & SKBR3 tumor bearing mice & i.v. & $20 \mu \mathrm{g}$ of nanostructures & - & Y & {$[50]$} \\
\hline IR780 loaded HSA-based nanoparticles & $\mathrm{BxPC}-3$ tumor bearing mice & i.v. & $22.5 \mu \mathrm{g}$ & - & Y & [109] \\
\hline IR780 and DOX loaded PEGylated micelles & MCF-7/DOX tumor bearing mice & i.v. & $\begin{array}{l}20 \mu \mathrm{g} \\
\text { (twice) }\end{array}$ & - & Y & [88] \\
\hline IR780 and Cabazitaxel loaded PEGylated micelles & $4 \mathrm{~T} 1$ tumor bearing mice & i.v. & $100 \mu \mathrm{g}$ & - & Y & [95] \\
\hline $\begin{array}{l}\text { IR780 and Perfluoropentane loaded cRCD- } \\
\text { functionalized PEGylated nanoparticles }\end{array}$ & B16 tumor bearing mice & i.v. & $\begin{array}{c}1 \mathrm{mg} \text { of } \\
\text { nanostructures }\end{array}$ & Y & Y & [38] \\
\hline $\begin{array}{l}\text { CPT-ss-CPT and Lactobionic acid-IR780 mixed } \\
\text { nanoparticles }\end{array}$ & Hep1-6 tumor bearing mice & i.v. & $1.5 \mu \mathrm{mol} \mathrm{kg}{ }^{-1}$ & - & Y & [96] \\
\hline IR780 and AMD3100 loaded liposomes $\left.{ }^{f}\right)$ & $4 \mathrm{Tl} /$ Luc tumor bearing mice & i.v. & $0.3 \mathrm{mg} \mathrm{kg}^{-1}$ & - & Y & {$[85]$} \\
\hline IR780 and DOX loaded PEGylated micelles ${ }^{\mathrm{g}}$ ) & $4 \mathrm{~T} 1$ tumor bearing mice & i.v. & $0.3 \mathrm{mg} \mathrm{kg}^{-1}$ & Y & Y & [53] \\
\hline $\begin{array}{l}\text { IR780 and SPION loaded PEGylated HSA } \\
\text { nanoparticles }\end{array}$ & CT-26 tumor bearing mice & i.v. & $0.3 \mathrm{mg} \mathrm{kg}^{-1}$ & - & Y & {$[90]$} \\
\hline IR780 and Sunitinib loaded liposomes ${ }^{\text {h) }}$ & $4 \mathrm{~T} 1$ tumor bearing mice & i.v. & $0.3 \mathrm{mg} \mathrm{kg}^{-1}$ & - & Y & {$[52]$} \\
\hline IR780 loaded CXCR4-targeted liposomesi) & $4 \mathrm{~T} 1$-luc tumor bearing mice & i.v. & $0.3 \mathrm{mg} \mathrm{kg}^{-1}$ & - & Y & {$[86]$} \\
\hline IR780 loaded CXCR4-targeted liposomesi) & HSC-T6 tumor bearing mice & i.v. & $0.3 \mathrm{mg} \mathrm{kg}^{-1}$ & - & Y & [110] \\
\hline IR780 loaded transferrin nanoparticles & CT-26 tumor bearing mice & i.v. & $0.3 \mathrm{mg} \mathrm{kg}^{-1}$ & - & Y & [97] \\
\hline DOX loaded IR780-micelles & $\begin{array}{c}\text { MCF-7, } \mathrm{H} 22 \text { and } 4 \mathrm{~T} 1 \text { tumor bearing } \\
\text { mice }\end{array}$ & i.v. & $0.5 \mathrm{mg} \mathrm{kg}^{-1}$ & - & Y & [102] \\
\hline $\begin{array}{l}\text { IR780 and Ce6 loaded TPP-functionalized } \\
\text { PEGylated liposomes }{ }^{k)}\end{array}$ & HeLa tumor bearing mice & i.v. & $0.5 \mathrm{mg} \mathrm{kg}^{-1}$ & Y & Y & {$[51]$} \\
\hline $\begin{array}{l}\text { IR780 loaded iRGD-functionalized Dextran- } \\
\text { poly(lysine)-based nanostructures incorporating } \\
\text { fluorocarbons }\end{array}$ & $4 \mathrm{~T} 1$ tumor bearing mice & i.v. & $0.5 \mathrm{mg} \mathrm{kg}^{-1}$ & Y & Y & [89] \\
\hline IR780 and Ce6 loaded HSA nanoparticles & CT-26 tumor bearing mice & i.v. & $0.7 \mathrm{mg} \mathrm{kg}^{-1}$ & - & Y & {$[82]$} \\
\hline IR780 loaded HA functionalized micelles & MDA-MB-231 tumor bearing mice & i.v. & $0.7 \mathrm{mg} \mathrm{kg}^{-1}$ & Y & Y & [83] \\
\hline DOX loaded PEG-IR780- $\mathrm{C}_{13}$-based liposomes') & CT-26 tumor bearing mice & i.v. & $\begin{array}{l}0.75 \mathrm{mg} \mathrm{kg}^{-1} \text { of } \\
\text { PEG-IR780-C }\end{array}$ & - & Y & [103] \\
\hline $\begin{array}{l}\text { IR780 loaded FA functionalized PECylated } \\
\text { liposomes }\end{array}$ & SKOV-3 tumor bearing mice & i.v. & $1 \mathrm{mg} \mathrm{kg}^{-1}$ & - & Y & {$[47]$} \\
\hline IR780 loaded Hb nanoparticles & CT-26 tumor bearing mice & via oral gavage & $1 \mathrm{mg} \mathrm{kg}^{-1}$ & - & Y & [105] \\
\hline IR780 loaded lipid nanocarriers ${ }^{\mathrm{m} \text { ) }}$ & CT-26 tumor bearing mice & via oral gavage & $1 \mathrm{mg} \mathrm{kg}^{-1}$ & - & Y & [104] \\
\hline IR780 loaded PEGylated micelles ${ }^{\text {n) }}$ & MCF-7 tumor bearing mice & i.v. & $1 \mathrm{mg} \mathrm{kg}^{-1}$ & - & Y & [101] \\
\hline PEG-IR780- $\mathrm{C}_{13}$ micelles & RENCA tumor bearing mice & i.v. & $\begin{array}{l}1 \mathrm{mg} \mathrm{kg}^{-1} \text { of } \\
\text { nanostructures }\end{array}$ & - & Y & [94] \\
\hline IR780 loaded PEGylated liposomes & $4 \mathrm{~T} 1 /$ Luc tumor bearing mice & i.v. & $1.1 \mathrm{mg} \mathrm{kg}^{-1}$ & Y & Y & [106] \\
\hline $\begin{array}{l}\text { IR780 and PTX loaded isopentyl nitrite-HSA } \\
\text { nanoparticles }\end{array}$ & $4 \mathrm{~T} 1$ tumor bearing mice & i.v. & $1.5 \mathrm{mg} \mathrm{kg}^{-1}$ & - & Y & [100] \\
\hline $\begin{array}{l}\text { RBC membrane-coated IR780 and DTX loaded } \\
\text { PCL-PEG-PCL nanoparticles }\end{array}$ & MCF-7 tumor bearing mice & i.v. & $1.6 \mathrm{mg} \mathrm{kg}^{-1}$ & Y & Y & [49] \\
\hline
\end{tabular}


Table 3. Continued.

\begin{tabular}{|c|c|c|c|c|c|c|}
\hline Heptamethine cyanine based nanostructures & Tumor model & Administration route & Dose $^{\text {a) }}$ & PAI & $\begin{array}{l}\text { NIR fluorescence } \\
\text { imaging }\end{array}$ & Ref. \\
\hline IR780 loaded FA-Graphene quantum dots & HeLa tumor bearing mice & i.v. & $\begin{array}{l}2 \mathrm{mg} \mathrm{kg}^{-1} \text { of } \\
\text { nanostructures }\end{array}$ & - & Y & {$[84]$} \\
\hline $\begin{array}{l}\text { IR780 and DOX loaded PDA-coated } \\
\text { TPGS- micelles }\end{array}$ & MCF-7/ADR tumor bearing mice & i.v. & $\begin{array}{l}3 \mathrm{mg} \mathrm{kg}^{-1} \text { of } \\
\text { nanostructures }\end{array}$ & - & Y & [93] \\
\hline IR780 and DTX loaded HSA nanoparticles & 22RV1 tumor bearing mice & i.v. & $3 \mathrm{mg} \mathrm{kg}^{-1}$ & - & Y & [91] \\
\hline Cypate incorporating PEGylated nanoparticles $\left.{ }^{\circ}\right)$ & HeLa tumor bearing mice & i.v. & $23 \mu \mathrm{g}$ & - & Y & [111] \\
\hline PEG-Cypate micelles & B16F10 tumor bearing mice & i.v. & $0.25 \mathrm{mg} \mathrm{kg}^{-1}$ & - & Y & {$[57]$} \\
\hline $\begin{array}{l}\text { Cypate loaded Folate-functionalized PEGylated } \\
\text { based micelles }\end{array}$ & MDA-MB-231 tumor bearing mice & i.v. & $\begin{array}{l}1 \mathrm{mg} \mathrm{kg}^{-1} \text { of } \\
\text { nanostructures }\end{array}$ & - & Y & {$[44]$} \\
\hline Cypate-BSA based nanoparticles & $4 \mathrm{Tl}$ tumor bearing mice & i.v. & $1.5 \mathrm{mg} \mathrm{kg}^{-1}$ & Y & Y & {$[54]$} \\
\hline Cypate loaded HA based nanoparticles & MCF-7 tumor bearing mice & i.v. & $2 \mathrm{mg} \mathrm{kg}^{-1}$ & - & Y & {$[43]$} \\
\hline HA coated Melittin/Cypate nanoagents & $4 \mathrm{~T} 1$ tumor bearing mice & i.v. & $3 \mathrm{mg} \mathrm{kg}^{-1}$ & - & $Y$ & [36] \\
\hline Cypate and DPAE loaded PEGylated micelles ${ }^{\mathrm{p})}$ & $4 \mathrm{Tl}$ tumor bearing mice & i.v. & $7.5 \mathrm{mg} \mathrm{kg}^{-1}$ & - & Y & [112] \\
\hline $\begin{array}{l}\text { Cypate and Pt(IV) prodrug loaded PEGylated } \\
\text { micelles }{ }^{9)}\end{array}$ & A549R tumor bearing mice & i.v. & $7.5 \mathrm{mg} \mathrm{kg}^{-1}$ & - & Y & {$[55]$} \\
\hline Cypate and PTX loaded PEGylated nanorparticles ${ }^{r)}$ & $4 \mathrm{Tl}$ tumor bearing mice & i.v. & $7.5 \mathrm{mg} \mathrm{kg}^{-1}$ & - & Y & {$[56]$} \\
\hline Cypate and 17AAG loaded PEGylated micelles ${ }^{\mathrm{s})}$ & A549 tumor bearing mice & i.v. & $7.5 \mathrm{mg} \mathrm{kg}^{-1}$ & - & Y & [113] \\
\hline Cypate-PEG-GO & $4 \mathrm{Tl}$ tumor bearing mice & i.v. & $7.5 \mathrm{mg} \mathrm{kg}^{-1}$ & - & Y & [114] \\
\hline Cypate and Ce6 loaded PEGylated micelles9) & $4 \mathrm{Tl}$ tumor bearing mice & i.v. & $7.5 \mathrm{mg} \mathrm{kg}^{-1}$ & Y & Y & [115] \\
\hline $\begin{array}{l}\text { DOX loaded PEGylated cypate- mesoporous silica } \\
\text { nanoparticles }\end{array}$ & $4 \mathrm{Tl}$ tumor bearing mice & i.v. & $8.5 \mathrm{mg} \mathrm{kg}^{-1}$ & - & Y & [116] \\
\hline Cypate loaded PEGylated micellesq) & A549 tumor bearing mice & i.v. & $10 \mathrm{mg} \mathrm{kg}^{-1}$ & - & Y & [117] \\
\hline IR808-HA nanoparticles & A549 tumor bearing mice & i.v. & $10 \mu \mathrm{g}$ & Y & Y & [30] \\
\hline $\begin{array}{l}\text { IR808-PEG-PSMA coated } \\
\text { MnO nanoparticles }\end{array}$ & MCF-7 tumor bearing mice & i.v. & $50 \mu \mathrm{g}$ & Y & Y & [37] \\
\hline $\begin{array}{l}\text { IR808-mesoporous silica shell coated Gd silicate } \\
\text { nanoparticles }\end{array}$ & LLC/LL2 tumor bearing mice & i.v. & $0.25 \mu \mathrm{mol} \mathrm{kg}{ }^{-1}$ & - & Y & [118] \\
\hline PTX loaded IR808-HGC micelles & $4 \mathrm{~T} 1$ and SCC7 tumor bearing mice & i.v. & $0.12 \mathrm{mg} \mathrm{kg}^{-1}$ & - & Y & [119] \\
\hline IR808-PEG-DSPE coated SPIONs & SCC7 tumor bearing mice & i.v. & $0.2 \mathrm{mg} \mathrm{kg}^{-1}$ & - & Y & [120] \\
\hline IR808-PEI-PEG-GO & A549 and Lewis tumor bearing mice & i.v. & $\begin{array}{l}0.5 \mathrm{mg} \mathrm{kg}^{-1} \text { of } \\
\text { nanostructures }\end{array}$ & - & Y & [21] \\
\hline IR820-poly(histidine)-DPPE ${ }^{\mathrm{t}}$ nanoparticles & MCF-7 tumor bearing mice & i.v. & N.D. & - & Y & [121] \\
\hline PEGylated IR820-micelles ${ }^{\text {u) }}$ & $\mathrm{BxPC}-3$ tumor bearing mice & i.v. & $15 \mu \mathrm{g}$ of IR820-COOH & - & Y & [122] \\
\hline IR820 loaded ferritin nanocages & $4 \mathrm{~T} 1$ tumor bearing mice & i.v. & $400 \mu \mathrm{g}$ & Y & - & {$[60]$} \\
\hline IR820-PTX nanoparticles & $4 \mathrm{Tl}$ tumor bearing mice & i.v. & $\begin{array}{l}4.2 \mathrm{mg} \mathrm{kg}^{-1} \text { of } \\
\text { nanostructures }\end{array}$ & - & Y & {$[61]$} \\
\hline $\begin{array}{l}\text { PECylated IR820-conjugated poly ( } \beta \text {-amine ester) } \\
\text { and ZnPP-poly ( } \beta \text {-amine ester) micelles }\end{array}$ & A549 tumor bearing mice & i.v. & $\begin{array}{c}5 \mathrm{mg} \mathrm{kg}^{-1} \text { of } \\
\text { nanostructures }\end{array}$ & Y & - & [7] \\
\hline IR825 and CA4 loaded siHSP70/PEI-PLA micelles & MDA-MB-231 tumor bearing mice & i.v. & N.D. & Y & - & [123] \\
\hline IR825 and DOX loaded PEG-PAA-PEI aggregates & $4 \mathrm{Tl}$ tumor bearing mice & i.v. & N.D. & $\mathrm{Y}$ & - & [124] \\
\hline IR825 loaded TCPP crosslinked PEGylated micelles & $4 \mathrm{~T} 1$ tumor bearing mice & i.v. & $100 \mu \mathrm{g}$ & Y & - & {$[33]$} \\
\hline PFOB loaded HA-IR825 nanoparticles & HT-29 tumor bearing mice & i.v. & $\begin{array}{c}500 \mu \mathrm{g} \text { of } \\
\text { nanostructures }\end{array}$ & Y & - & [125] \\
\hline dc-IR825 and 17AAG loaded HSA nanoparticles & $4 \mathrm{~T} 1$ tumor bearing mice & i.v. & $1 \mathrm{mg} \mathrm{kg}^{-1}$ & - & Y & {$[64]$} \\
\hline $\begin{array}{l}\text { IR825 and DOX loaded perylene diimide-based } \\
\text { nanoplatforms }\end{array}$ & U87MG tumor bearing mice & i.v. & $1 \mathrm{mg}$ of nanostructures & Y & - & [126] \\
\hline dc-IR825 loaded TPGS micelles & U14 tumor bearing mice & i.v. & $3 \mathrm{mg} \mathrm{kg}^{-1}$ & Y & Y & {$[65]$} \\
\hline PEG-IR825 and HA-PDA anchored rGO & MDA-MB-231 tumor bearing mice & i.v. & $\begin{array}{l}5 \mathrm{mg} \mathrm{kg}^{-1} \text { of } \\
\text { nanostructures }\end{array}$ & - & Y & [127] \\
\hline
\end{tabular}


Table 3. Continued.

\begin{tabular}{|c|c|c|c|c|c|c|}
\hline Heptamethine cyanine based nanostructures & Tumor model & Administration route & Dose $^{\text {a) }}$ & PAl & $\begin{array}{l}\text { NIR fluorescence } \\
\text { imaging }\end{array}$ & Ref. \\
\hline $\begin{array}{l}\text { mPEG-b-poly(L-aspartic acid sodium salt)-IR825) } \\
\text { conjugate micelles }\end{array}$ & U14 tumor bearing mice & i.v. & $\begin{array}{c}10 \mathrm{mg} \mathrm{kg}^{-1} \text { of } \\
\text { nanostructures }\end{array}$ & - & Y & [46] \\
\hline $\begin{array}{l}\text { me-IR } 825 \text { loaded Pluronic F-127 based } \\
\text { nanoparticles }\end{array}$ & U14 tumor bearing mice & i.v. & $\begin{array}{l}300 \mathrm{mg} \mathrm{kg}^{-1} \text { of } \\
\text { nanostructures }\end{array}$ & Y & Y & [66] \\
\hline IR775 loaded HSA-based nanoparticles & $4 \mathrm{~T} 1$ tumor bearing mice & i.v. & N.D. & - & Y & [128] \\
\hline IR775 loaded HSA-based nanoparticles & CT-26 tumor bearing mice & i.v. & N.D. & - & Y & [129] \\
\hline $\begin{array}{l}\text { IR783 conjugated with cRGD-PEG-dendritic } \\
\text { poly(lysine) }\end{array}$ & U87 tumor bearing mice & i.v. & $15 \mathrm{nmol}$ & - & Y & [70] \\
\hline IR797 loaded PEG-PMAO micelles & HeLa tumor bearing mice & i.v. & $42 \mathrm{nmol}$ & Y & Y & [67] \\
\hline IR775 loaded PEG-Hb nanoparticles & $\mathrm{H} 22$ tumor bearing mice & i.v. & $0.3 \mathrm{mg} \mathrm{kg}^{-1}$ & - & Y & [130] \\
\hline IR775 loaded mPEG-PCL nanoparticles & A2780/CDDP tumor bearing mice & i.v. & $0.75 \mathrm{mg} \mathrm{kg}^{-1}$ & - & Y & [10] \\
\hline $\begin{array}{l}\text { IR783-PEG-DSPE and CREKA }{ }^{v)} \text {-PEG-DSPE coated } \\
\text { oxidized MWNTs }{ }^{\mathrm{w})}\end{array}$ & A549 tumor bearing mice & i.v. & $\begin{array}{c}4 \mathrm{mg} \mathrm{kg}^{-1} \text { of } \\
\text { nanostructures }\end{array}$ & - & Y & [69] \\
\hline IRDye $800 \mathrm{CW}$ labeled PEGylated liposomes ${ }^{\mathrm{x}}$ ) & BLM tumor bearing mice & i.v. & $\begin{array}{c}1 \mu \mathrm{mol} \text { of } \\
\text { nanostructures }\end{array}$ & - & Y & [71] \\
\hline $\begin{array}{l}\text { IRDye } 800 \mathrm{CW} \text { labeled PSMA-targeted PEGylated } \\
\text { starch coated } \mathrm{Fe}_{3} \mathrm{O}_{4} \text { nanoparticles }\end{array}$ & PC3 tumor bearing mice & i.v. & $\begin{array}{c}250 \mu \mathrm{g} \text { of } \\
\text { nanostructures }\end{array}$ & - & Y & [72] \\
\hline GX1 peptide-IRDye 800CW-PVA/PLA nanoparticles & U87MG tumor bearing mice & i.v. & $1 \mathrm{mg}$ & - & Y & [131] \\
\hline $\begin{array}{l}\text { IRDye } 800 \mathrm{CW} \text { labeled HA-PEG coated hollow Prus- } \\
\text { sian blue nanoparticlesy) }\end{array}$ & HeLa tumor bearing mice & i.v. & $\begin{array}{l}10 \mathrm{mg} \mathrm{kg}^{-1} \text { of } \\
\text { nanostructures }\end{array}$ & - & Y & [132] \\
\hline
\end{tabular}

a) Dose of heptamethine cyanine (unless stated otherwise); ${ }^{b}$ )IR825 derivative modified with a primary amine; c) formulated using DPPC, 1-myristoyl-2-palmitoyl-snglycero-3-phosphocholine, and DSPE-PEG; ${ }^{\text {d) }}$ formulated with DPPC, cholesterol, DSPE-PEG and DSPE-PEG-FA; e) formulated with distearoylphosphatidylcholine (DSPC), cholesterol and DSPE-PEG; ${ }^{\text {f) }}$ prepared using soybean phospholipids, trilaurin, cholesterol and sodium dodecyl sulfate; ${ }^{\text {g) }}$ formulated using PEG-poly (acrylamide-co-acrylonitrile-co-vinylimidazole); h)formulated using soybean phospholipids; i)formulated with phosphatidylcholine, medium-chain triglycerides, trilaurin and AMD3100; i)formulated with egg phosphatidylcholine, cholesterol and AMD3100; k) formulated with DPPC, cholesterol, DSPE-PEG and DSPE-PEG-TPP; ')formulated using lecithin, cholesterol and PEG-IR780- $\mathrm{C}_{13}$ conjugate; ${ }^{\mathrm{m})}$ formulated with soy lecithin, trilaurin, and Labrafac CC; ${ }^{n}$ ) prepared using poly(2-hydroxyethyl methacrylate)-g-(PAA-PEG); ${ }^{\circ}$ formulated with PEG-bilirubin and biotin-PEG-bilirubin; P) formulated with PEG-PCL-poly((2-(piperidin-1-yl) ethyl methacrylate); 9) formulated with mPEG-poly (L-aspartic acid(decylamine)) (mPEG-PAsp(DA)); r)formulated with PEG-PCL-SS-P(N-isopropylacrylamide-co- $N, N$-dimethylacrylamide) (PEG-PCL-SS-P(NIPAM-co-DMA)); s)formulated with PEG$\mathrm{PCL} ;{ }^{\mathrm{t}}$ 1,2-dipalmitoyl-sn-glycero-3-phosphoethanolamine; u)formulated using PEG-polylactide (PLA)-co-poly(5-methyl-5-allyloxycarbonyl-1,3-dioxan-2-one)-g-(IR820-coGemcitabine)); ${ }^{v}$ Cys-Arg-Glu-Lys-Ala peptide; ${ }^{\text {w) }}$ multiwalled carbon nanotubes; ${ }^{\mathrm{x}}$ formulated with DPPC, DSPC, DSPE-PEC and 3-(2-pyridyl)-dithiopropionyl-PEG-DSPE; y) formulated by conjugating HA-g-PEC to PAH/PAA coated hollow prussian blue nanoparticles.

In another work, Valcourt et al. demonstrated that the PTT mediated by poly(lactic-co-glycolic acid) (PLGA) nanoparticles loaded with IR820 could induce tumors regression. ${ }^{[62]}$ Still, in order to achieve such effect, 4 different nanomaterials' administration and irradiation sessions were required.

In this way, IR820 based nanomaterials have also been combined with other therapeutic agents with the intent to improve their therapeutic efficacy (Table 6). In this regard, Li et al. improved the efficacy of IR820 loaded Lyp-1 modified micelles by incorporating docetaxel in the nanoformulation. ${ }^{[63]}$ In vivo, the combinatorial chemo-PTT/PDT mediated by these micelles induced tumor eradication using a relatively low dose of the photo-responsive agent ( $2 \mathrm{mg} \mathrm{kg}^{-1}$ of IR820).

\subsection{IR825 Based Nanomaterials}

The loading of IR825 into different nanostructures for application in cancer PTT/PDT and imaging (NIR fluorescence imaging and PAI) has also been described in several reports ${ }^{[27,33,46]}$-see details in Tables 7 and 3. Alternatively, Pan et al. prepared an IR825-derivative modified with a primary amine in order to conjugate it to mPEG-poly(L-aspartic acid sodium salt), rendering an amphiphilic copolymer capable of self-assembling into micelles. ${ }^{[46]}$ In vivo, the IR825-micelles displayed a long blood circulation time, achieving a high tumor accumulation that allowed tumors' NIR imaging over time. Furthermore, the PTT mediated by the IR825-micelles induced tumors eradication while the combination of primary amine modified-IR825 with NIR light did not produce a therapeutic effect due to the low tumor uptake of the free dye. Furthermore, the $\mathrm{Wu}$ group also prepared other IR825 derivatives termed as dc-IR825[64,65] and me-IR825, ${ }^{[66]}$ and whose encapsulation in nanomaterials enabled an effective PTT/PDT in vivo.

Furthermore, combinatorial cancer phototherapies based on IR825-incorporating nanomaterials have also been developed by including additional agents in the nanomaterials (Table 7). For instance, Liu et al. produced PEGylated polymeric micelles loaded with IR825 and cross-linked with 5,10,15,20-tetrakis(4carboxyphenyl) porphyrin (TCPP, a porphyrin derivative that is also a $660 \mathrm{~nm}$ absorbing photodynamic agent) for application in cancer PTT/PDT. ${ }^{[33]}$ These micelles were able to reach the tumor tissue, enabling its visualization by PAI. Subsequently, the irradiation of the tumor zone with NIR and $660 \mathrm{~nm}$ lights 

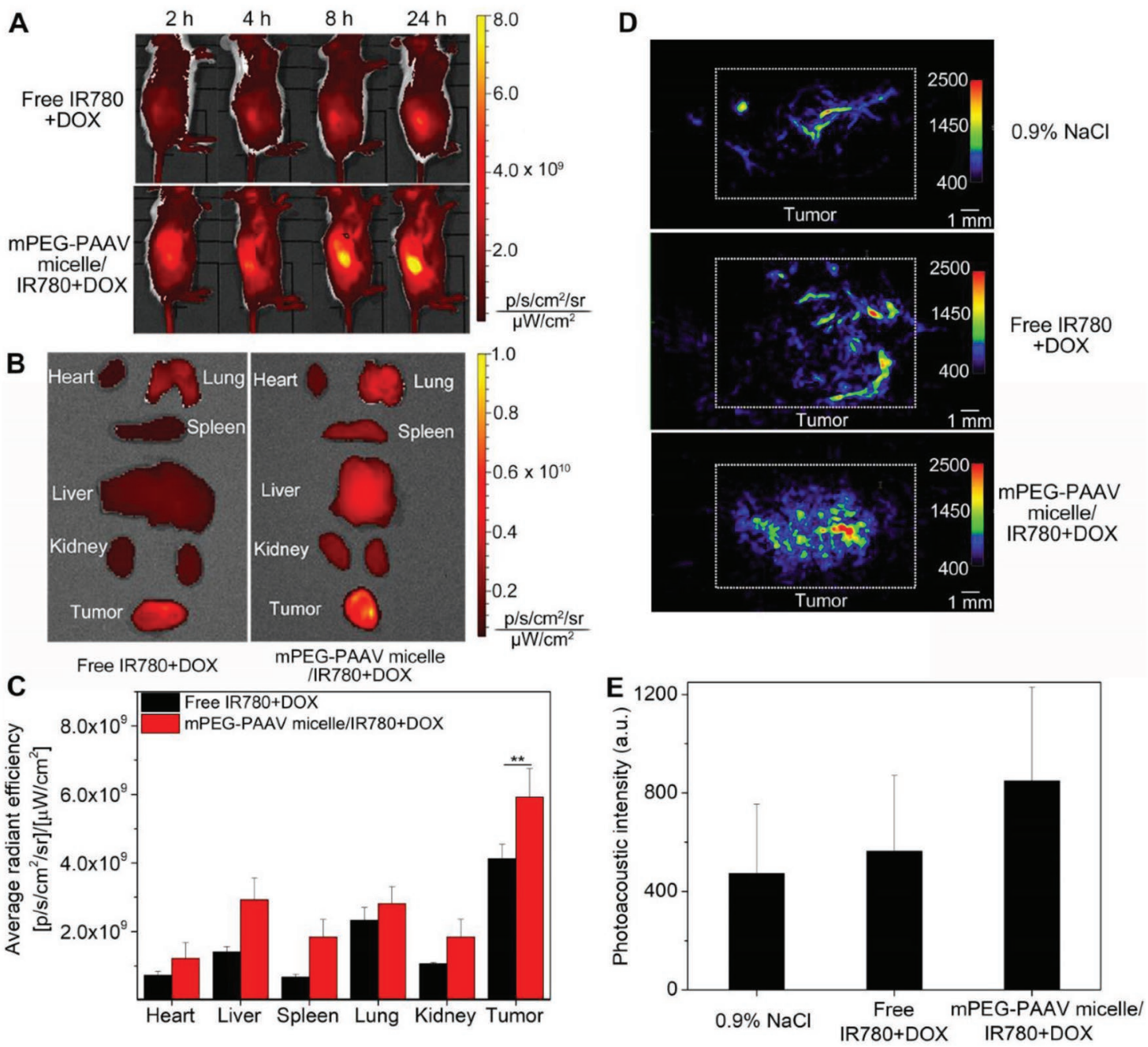

Figure 3. Imaging capabilities of the PEGylated micelles incorporating IR780 and DOX. A) NIR fluorescence imaging of mice treated with different formulations. B) Ex vivo NIR fluorescence imaging and C) quantitative IR780 tumor uptake. D) PAI of the tumors and E) photoacoustic intensity at the tumor site after the different treatments. mPEG-PAAV micelles/IR780+DOX: PEGylated micelles incorporating IR780 and DOX. Reproduced with permission. ${ }^{[53]}$ Copyright 2018, Ivyspring International Publishers.

produced a photothermal-photodynamic effect that reduced tumors' growth. In contrast, a weaker therapeutic effect was observed on mice solely irradiated with NIR light (PTT) and $660 \mathrm{~nm}$ light (PDT).

\subsection{Other Heptamethine Cyanine Based Nanomaterials}

Nanomaterials incorporating IR775, IR797, and IR806 have not yet been as widely explored for cancer theragnostic as those described above (Tables 8 and 3). ${ }^{[10,67,68]}$ Nevertheless, these have demonstrated promising results which should motivate further investigation on their applicability for cancer PTT/PDT and imaging (Tables 8 and 3).

For instance, Duong et al. demonstrated that PEGpoly(caprolactone) (PCL) nanoparticles loaded with IR775 or IR797 possess optical properties that may enable their use for cancer NIR imaging and PTT/PDT. ${ }^{10]}$ In another work, Deng et al. prepared IR806 (a carboxylated IR780 derivative obtained by reacting IR780 with 4-mercaptobenzoic acid) and conjugated it to primary amine-capped PEGylated $\mathrm{MnFe}_{2} \mathrm{O}_{4}$ nanoparticles. ${ }^{[68]}$ This system displayed photodynamic (derived from IR806) and enhanced photothermal (arising from IR806 and $\mathrm{MnFe}_{2} \mathrm{O}_{4}$ ) capabilities, thus mediating an improved PTT/ PDT in vivo. ${ }^{68]}$

The labeling of other nanomaterials with IR783 ${ }^{[69,70]}$ and IRDye $800 \mathrm{CW}^{[71,72]}$ (Table 3) also enabled the analysis of nanomaterials' biodistribution and the visualization of the tumoral mass overtime.

\section{Conclusion and Outlook}

In this progress report, the recent advances regarding the use of nanomaterials incorporating prototypic NIR heptamethine cyanines for cancer phototheragnostic were analyzed.

IR780 based nanomaterials have been by far the most explored for cancer theragnostic. This fact can be explained 
Table 4. In vivo therapeutic performance of Cypate based nanostructures.

\begin{tabular}{|c|c|c|c|c|c|c|c|c|}
\hline $\begin{array}{l}\text { Cypate based } \\
\text { nanostructures }\end{array}$ & $\begin{array}{l}\text { Phototherapy } \\
\text { modality }\end{array}$ & Tumor model & $\begin{array}{l}\text { Administration } \\
\text { route }\end{array}$ & Dose $^{\text {a) }}$ & Laser parameters & $\begin{array}{l}\text { Other therapeutic } \\
\text { molecules }\end{array}$ & Therapeutic effect & Ref. \\
\hline $\begin{array}{l}\text { Cypate loaded HA based } \\
\text { nanoparticles }\end{array}$ & PTT/PDT & $\begin{array}{l}\text { MCF-7 tumor bearing } \\
\text { mice }\end{array}$ & i.v. & $40 \mu \mathrm{g}$ & $\begin{array}{c}785 \mathrm{~nm} ; 0.5 \mathrm{~W} \mathrm{~cm}^{-2} \\
5 \mathrm{~min}\end{array}$ & - & Tumor eradication & {$[43]$} \\
\hline $\begin{array}{l}\text { Cypate-BSA based } \\
\text { nanoparticles }\end{array}$ & PTT & $4 \mathrm{Tl}$ tumor bearing mice & i.v. & $1.5 \mathrm{mg} \mathrm{kg}^{-1}$ & $\begin{array}{c}785 \mathrm{~nm} ; 1.5 \mathrm{~W} \mathrm{~cm}^{-2} \\
3 \mathrm{~min}\end{array}$ & - & Tumor eradication & [54] \\
\hline PEG-Cypate micelles & PTT/PDT & $\begin{array}{l}\text { B16F10 tumor bearing } \\
\text { mice }\end{array}$ & i.v. & $5 \mathrm{mg} \mathrm{kg}^{-1}$ & $\begin{array}{c}808 \mathrm{~nm} ; 0.4 \mathrm{~W} \mathrm{~cm}^{-2} \\
10 \mathrm{~min}\end{array}$ & - & Tumor eradication & {$[57]$} \\
\hline Cypate-PEG- GO & PTT & $4 \mathrm{Tl}$ tumor bearing mice & i.v. & $7.5 \mathrm{mg} \mathrm{kg}^{-1}$ & $\begin{array}{c}785 \mathrm{~nm} ; 1.0 \mathrm{~W} \mathrm{~cm}^{-2} \\
3 \mathrm{~min}\end{array}$ & GO & Tumor eradication & [114] \\
\hline $\begin{array}{l}\text { Cypate and PTX } \\
\text { loaded PEGylated } \\
\text { nanoparticles }^{\text {b) }}\end{array}$ & РTT & $4 \mathrm{~T} 1$ tumor bearing mice & i.v. & $7.5 \mathrm{mg} \mathrm{kg}^{-1}$ & $\begin{array}{c}785 \mathrm{~nm} ; 1.0 \mathrm{~W} \mathrm{~cm}^{-2} \\
5 \mathrm{~min}\end{array}$ & PTX & Tumor eradication & {$[56]$} \\
\hline $\begin{array}{l}\text { Cypate and 17AAG } \\
\text { loaded PEGylated } \\
\text { micelles }^{c)}\end{array}$ & PTT/PDT & $\begin{array}{l}\text { A549 tumor bearing } \\
\text { mice }\end{array}$ & i.v. & $\begin{array}{l}7.5 \mathrm{mg} \mathrm{kg}^{-1} \\
(3 \text { times })\end{array}$ & $\begin{array}{c}785 \mathrm{~nm} ; 1.5 \mathrm{~W} \mathrm{~cm}^{-2} \\
3 \mathrm{~min} \\
(3 \text { times })\end{array}$ & $17 A A G$ & Tumor eradication & [113] \\
\hline $\begin{array}{l}\text { Cypate and Pt(IV) pro- } \\
\text { drug loaded PEGylated } \\
\text { micelles }^{\text {d) }}\end{array}$ & PTT/PDT & $\begin{array}{l}\text { A549R tumor bearing } \\
\text { mice }\end{array}$ & i.v. & $\begin{array}{l}7.5 \mathrm{mg} \mathrm{kg}^{-1} \\
(3 \text { times })\end{array}$ & $\begin{array}{c}785 \mathrm{~nm} ; 1.5 \mathrm{~W} \mathrm{~cm}^{-2} \\
3 \mathrm{~min} \\
\text { (3 times) }\end{array}$ & $\mathrm{Pt}(\mathrm{IV})$ prodrug & Tumor eradication & [55] \\
\hline $\begin{array}{l}\text { DOX loaded PEGylated } \\
\text { Cypate- mesoporous } \\
\text { silica nanoparticles }\end{array}$ & PTT/PDT & $4 \mathrm{~T} 1$ tumor bearing mice & i.v. & $8.5 \mathrm{mg} \mathrm{kg}^{-1}$ & $\begin{array}{c}785 \mathrm{~nm} ; 1.5 \mathrm{~W} \mathrm{~cm}^{-2} \\
5 \mathrm{~min} \\
\text { (twice) }\end{array}$ & DOX & Tumor eradication & [116] \\
\hline $\begin{array}{l}\text { HA coated Melittin/ } \\
\text { Cypate nanoagents }\end{array}$ & РTT & $4 \mathrm{~T} 1$ tumor bearing mice & i.v. & $3 \mathrm{mg} \mathrm{kg}^{-1}$ & $\begin{array}{c}808 \mathrm{~nm} ; 1.0 \mathrm{~W} \mathrm{~cm}^{-2} \\
10 \mathrm{~min}\end{array}$ & Melittin & Tumor regression & [36] \\
\hline $\begin{array}{l}\text { DTX loaded iRGD- } \\
\text { Cypate- PAMAM } \\
\text { dendrimers }\end{array}$ & PTT/PDT & $\begin{array}{l}\text { HepG2 tumor bearing } \\
\text { mice }\end{array}$ & i.v. & $\begin{array}{l}6.7 \mathrm{mg} \mathrm{kg}^{-1} \\
\text { (every } 5 \text { days) }\end{array}$ & $\begin{array}{c}808 \mathrm{~nm} ; 1.6 \mathrm{~W} \mathrm{~cm}^{-2} \\
5 \mathrm{~min} \\
\text { (every } 5 \text { days) }\end{array}$ & DTX & Tumor regression & [32] \\
\hline $\begin{array}{l}\text { Cypate and DPAE loaded } \\
\text { PECylated micellese) }\end{array}$ & PTT/PDT & $4 \mathrm{Tl}$ tumor bearing mice & i.v. & $\begin{array}{l}7.5 \mathrm{mg} \mathrm{kg}^{-1} \\
\text { (twice) }\end{array}$ & $\begin{array}{c}808 \mathrm{~nm} ; 1.5 \mathrm{~W} \mathrm{~cm}^{-2} \\
5 \mathrm{~min}\end{array}$ & DPAE & Tumor regression & [112] \\
\hline $\begin{array}{l}\text { Cypate and DOX loaded } \\
\text { PECylated liposomes }{ }^{f)}\end{array}$ & PTT & $4 \mathrm{~T} 1$ tumor bearing mice & i.t. & $\begin{array}{l}10 \mathrm{mg} \mathrm{kg}^{-1} \text { of } \\
\text { DOX }\end{array}$ & $\begin{array}{c}785 \mathrm{~nm} ; 1.6 \mathrm{~W} \mathrm{~cm}^{-2} \\
5 \mathrm{~min}\end{array}$ & DOX & Tumor regression & [133] \\
\hline $\begin{array}{l}\text { Cypate loaded PEGylated } \\
\text { micelles }^{\text {d) }}\end{array}$ & PTT & $\begin{array}{l}\text { A549 tumor bearing } \\
\text { mice }\end{array}$ & i.v. & $\begin{array}{l}10 \mathrm{mg} \mathrm{kg}^{-1} \\
(3 \text { times })\end{array}$ & $\begin{array}{c}785 \mathrm{~nm} ; 1.0 \mathrm{~W} \mathrm{~cm}^{-2} \\
5 \mathrm{~min} \\
(3 \text { times })\end{array}$ & - & Tumor regression & [117] \\
\hline $\begin{array}{l}\text { PEGylated Cypate and } \\
\text { DOX based micelles }\end{array}$ & PTT & $\begin{array}{l}\text { MCF-7/ADR tumor } \\
\text { bearing mice }\end{array}$ & i.v. & $\begin{array}{l}10 \mathrm{mg} \mathrm{kg}^{-1} \\
(3 \text { times })\end{array}$ & $\begin{array}{c}808 \mathrm{~nm} ; 16 \mathrm{~W} \mathrm{~cm}{ }^{-2} \\
2 \mathrm{~min} \\
(3 \text { times })\end{array}$ & DOX & $\begin{array}{l}\text { Tumor growth } \\
\text { inhibition }\end{array}$ & {$[58]$} \\
\hline $\begin{array}{l}\text { Cypate-silk fibroin } \\
\text { nanoparticles }\end{array}$ & PTT & $\begin{array}{l}\text { K7M2 tumor bearing } \\
\text { mice }\end{array}$ & i.v. & $\begin{array}{c}10 \mu \mathrm{g} \text { of } \\
\text { nanostructures }\end{array}$ & $\begin{array}{c}808 \mathrm{~nm} ; 0.75 \mathrm{~W} \mathrm{~cm}^{-2} \\
10 \mathrm{~min}\end{array}$ & - & $\begin{array}{l}\text { Tumor growth } \\
\text { reduction }\end{array}$ & [134] \\
\hline $\begin{array}{l}\text { Cypate and Ce6 loaded } \\
\text { PEGylated micelles }{ }^{\text {d) }}\end{array}$ & PTT/PDT & $4 \mathrm{~T} 1$ tumor bearing mice & i.v. & $\begin{array}{l}7.5 \mathrm{mg} \mathrm{kg}^{-1} \\
(3 \text { times) }\end{array}$ & $\begin{array}{c}785 \mathrm{~nm} ; 1.0 \mathrm{~W} \mathrm{~cm}^{-2} \\
5 \mathrm{~min} \\
660 \mathrm{~nm} ; 1.0 \mathrm{~W} \mathrm{~cm}^{-2} \\
10 \mathrm{~min} \\
\text { (3 times) }\end{array}$ & Ce6 & $\begin{array}{l}\text { Tumor growth } \\
\text { reduction }\end{array}$ & [115] \\
\hline $\begin{array}{l}\text { DOX loaded TPGS } \\
\text { coated Cypate-mesopo- } \\
\text { rous silica nanoparticles }\end{array}$ & РТT & $4 \mathrm{~T} 1$ tumor bearing mice & i.v. & $\begin{array}{l}10 \mathrm{mg} \mathrm{kg}^{-1} \text { of } \\
\text { DOX } \\
\text { (3 times) }\end{array}$ & $\begin{array}{c}808 \mathrm{~nm} ; 2.0 \mathrm{~W} \mathrm{~cm}^{-2} \\
2 \mathrm{~min} \\
(3 \text { times })\end{array}$ & $\begin{array}{l}\text { DOX } \\
\text { TPGS }\end{array}$ & $\begin{array}{l}\text { Tumor growth } \\
\text { reduction }\end{array}$ & [135] \\
\hline
\end{tabular}

a) Dose of heptamethine cyanine (unless stated otherwise); b)formulated with PEG-PCL-SS-P(NIPAM-co-DMA); c)formulated with PEG-PCL; d)formulated with mPEGPAsp(DA); e)formulated with PEG-PCL-poly ((2-(piperidin-1-yl) ethyl methacrylate); f) formulated with DPPC, cholestherol, DSPE-PEG and $\mathrm{NH}_{4} \mathrm{HCO}_{3}$; g) formulated with a PEGylated Cypate amphiphilic conjugate and Pluronic P123-DOX based conjugate. 
Table 5. In vivo therapeutic performance of IR808 based nanostructures.

\begin{tabular}{|c|c|c|c|c|c|c|c|c|}
\hline $\begin{array}{l}\text { IR808 based } \\
\text { nanostructures }\end{array}$ & $\begin{array}{l}\text { Phototherapy } \\
\text { modality }\end{array}$ & Tumor model & $\begin{array}{l}\text { Administration } \\
\text { route }\end{array}$ & Dose $^{a)}$ & Laser parameters & $\begin{array}{l}\text { Other therapeutic } \\
\text { molecules }\end{array}$ & Therapeutic effect & Ref. \\
\hline $\begin{array}{l}\text { IR808-PEG-DSPE coated } \\
\text { SPIONs }\end{array}$ & PTT & $\begin{array}{l}\text { SCC7 tumor } \\
\text { bearing mice }\end{array}$ & i.t. & N.D. & $\begin{array}{c}808 \mathrm{~nm} ; 1.0 \mathrm{~W} \mathrm{~cm}{ }^{-2} \\
10 \mathrm{~min}\end{array}$ & - & Tumor eradication & [120] \\
\hline IR808-HA nanoparticles & PTT & $\begin{array}{l}\text { A549 tumor } \\
\text { bearing mice }\end{array}$ & i.v. & $36 \mu g$ & $\begin{array}{c}808 \mathrm{~nm} ; 0.8 \mathrm{~W} \mathrm{~cm}{ }^{-2} \\
5 \mathrm{~min}\end{array}$ & - & Tumor eradication & {$[30]$} \\
\hline $\begin{array}{l}\text { IR808-PEG-PSMA }{ }^{\text {b) }} \text { coated } \\
\text { MnO nanoparticles }\end{array}$ & PTT/PDT & $\begin{array}{l}\text { MCF-7 tumor } \\
\text { bearing mice }\end{array}$ & i.v. & $50 \mu \mathrm{g}$ & $\begin{array}{c}808 \mathrm{~nm} ; 0.5 \mathrm{~W} \mathrm{~cm}{ }^{-2} \\
5 \mathrm{~min}\end{array}$ & $\begin{array}{c}\mathrm{MnO} \\
\text { nanoparticles }\end{array}$ & Tumor eradication & [37] \\
\hline IR808-PEI-PEG-GO & PTT/PDT & $\begin{array}{c}\text { A549 or Lewis } \\
\text { tumor bearing } \\
\text { mice }\end{array}$ & i.v. & $\begin{array}{l}10 \mathrm{mg} \mathrm{kg}^{-1} \text { of } \\
\text { nanostructures }\end{array}$ & $\begin{array}{c}808 \mathrm{~nm} ; 1.0 \mathrm{~W} \mathrm{~cm}{ }^{-2} \\
5 \mathrm{~min}\end{array}$ & GO & Tumor eradication & [21] \\
\hline $\begin{array}{l}\text { PTX loaded IR808-HGC) } \\
\text { micelles }\end{array}$ & PTT & $\begin{array}{l}\text { SCC7 tumor } \\
\text { bearing mice }\end{array}$ & i.t. & $\begin{array}{l}10 \mathrm{mg} \mathrm{kg}^{-1} \text { of } \\
\text { nanostructures }\end{array}$ & $\begin{array}{c}808 \mathrm{~nm} ; 1.0 \mathrm{~W} \mathrm{~cm}{ }^{-2} \\
5 \mathrm{~min}\end{array}$ & PTX & Tumor regression & [119] \\
\hline
\end{tabular}

a) Dose of heptamethine cyanine (unless stated otherwise); b) cumene terminated poly (styrene-co-maleic anhydride); c) $5 \beta$-cholanic acid-glycol chitosan conjugate.
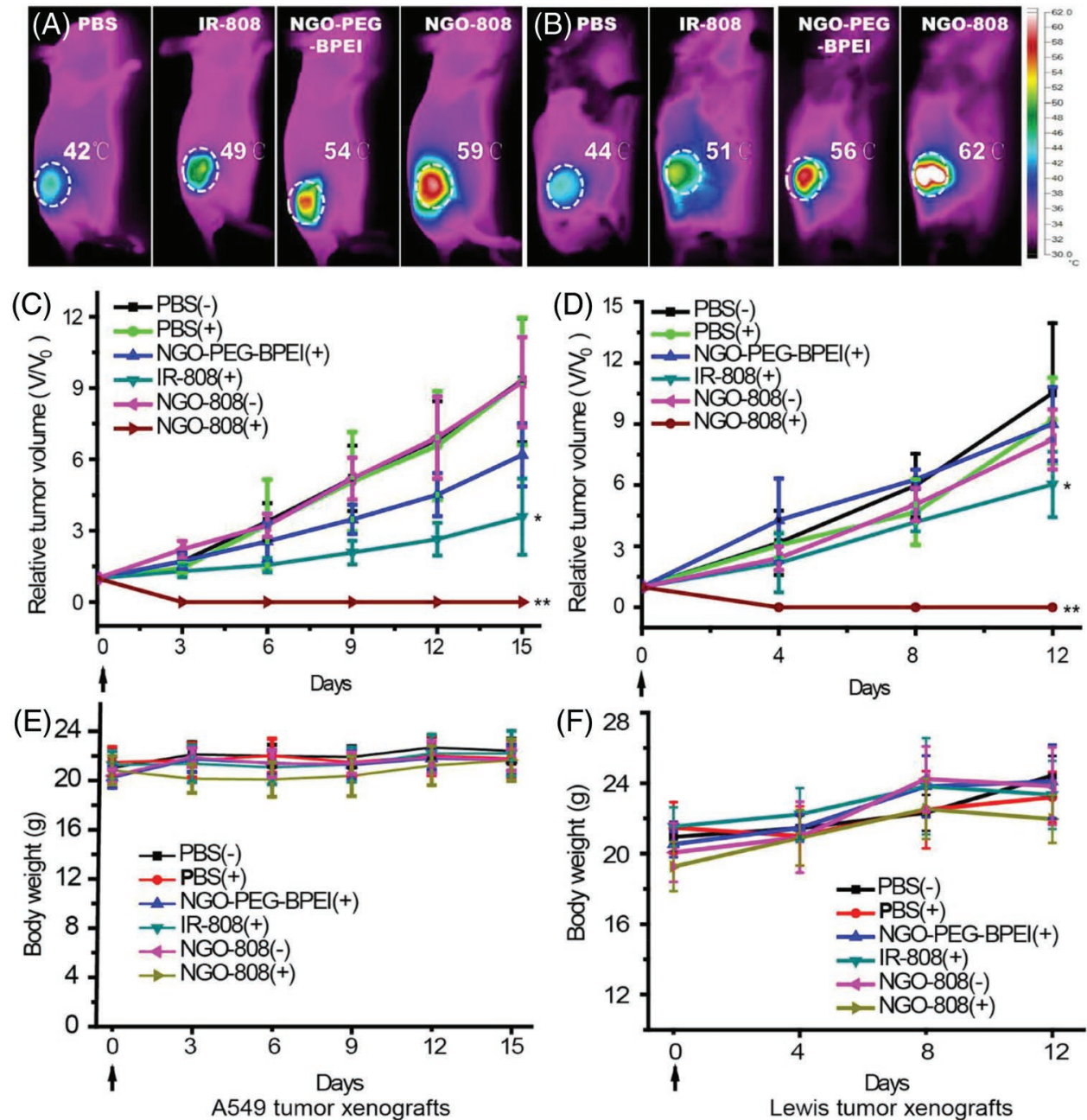

Figure 4. PTT/PDT mediated by IR808-PEI-PEG-GO. Thermal images of A) A549 and B) Lewis tumor bearing mice after the different treatments. C,D) Tumor volume and E,F) body weight changes of after the different treatments. PBS (-): PBS; PBS (+): PBS + NIR radiation; NGO-PEG-BPEI (+): PEI-PEG-GO + NIR radiation; IR808 (+): IR808 + NIR radiation; NGO-808 (-): IR808-PEI-PEG-GO; NGO-808 (+): IR808-PEI-PEG-GO + NIR radiation; NIR radiation: $808 \mathrm{~nm} ; 1.0 \mathrm{~W} \mathrm{~cm}^{-2} ; 5$ min. Reproduced with permission. ${ }^{[21]}$ Copyright 2016, American Chemical Society. 
Table 6. In vivo therapeutic performance of IR820 based nanostructures.

\begin{tabular}{|c|c|c|c|c|c|c|c|c|}
\hline $\begin{array}{l}\text { IR820 based } \\
\text { nanostructures }\end{array}$ & $\begin{array}{l}\text { Phototherapy } \\
\text { modality }\end{array}$ & Tumor model & $\begin{array}{l}\text { Administration } \\
\text { route }\end{array}$ & Dose $^{a)}$ & Laser parameters & $\begin{array}{l}\text { Other therapeutic } \\
\text { molecules }\end{array}$ & Therapeutic effect & Ref. \\
\hline $\begin{array}{l}\text { IR820 and Tane- } \\
\text { spimycin loaded } \\
\text { liposomes }^{\text {b) }}\end{array}$ & $\mathrm{PTT} / \mathrm{PDT}$ & $\begin{array}{l}\text { SCC-7 tumor } \\
\text { bearing mice }\end{array}$ & i.t. & $50 \mu \mathrm{g}$ & $\begin{array}{c}808 \mathrm{~nm} ; \\
2.0 \mathrm{~W} \mathrm{~cm}-3 \mathrm{~min} \\
660 \mathrm{~nm} ; \\
0.2 \mathrm{~W} \mathrm{~cm}^{-2} ; 3 \mathrm{~min}\end{array}$ & Tanespimycin & Tumor eradication & [136] \\
\hline $\begin{array}{l}\text { IR820 loaded ferritin } \\
\text { nanocages }\end{array}$ & PTT & $\begin{array}{l}4 \mathrm{~T} 1 \text { tumor bearing } \\
\text { mice }\end{array}$ & i.v. & $400 \mu \mathrm{g}$ & $\begin{array}{l}808 \mathrm{~nm} ; 0.5 \mathrm{~W} \\
\mathrm{~cm}^{-2} ; 10 \mathrm{~min}\end{array}$ & - & Tumor eradication & {$[60]$} \\
\hline $\begin{array}{l}\text { IR820 and DTX loaded } \\
\text { micelles }{ }^{c)}\end{array}$ & $\mathrm{PTT} / \mathrm{PDT}$ & $\begin{array}{l}4 \mathrm{~T} 1 \text { tumor bearing } \\
\text { mice }\end{array}$ & i.v. & $\begin{array}{l}2 \mathrm{mg} \mathrm{kg}^{-1} \\
\text { (3 times) }\end{array}$ & $\begin{array}{c}808 \mathrm{~nm} ; \\
2.5 \mathrm{~W} \mathrm{~cm}^{-2} ; 10 \\
\min \\
(3 \text { times })\end{array}$ & DTX & Tumor eradication & [63] \\
\hline $\begin{array}{l}\text { PEGylated IR820-conju- } \\
\text { gated poly }(\beta \text {-amine } \\
\text { ester) and } Z n \mathrm{nP}^{\mathrm{d})} \text { - } \\
\text { poly }(\beta \text {-amine ester }) \\
\text { micelles }\end{array}$ & PTT & $\begin{array}{l}\text { A549 tumor } \\
\text { bearing mice }\end{array}$ & i.v. & $\begin{array}{c}5 \mathrm{mg} \mathrm{kg}^{-1} \text { of } \\
\text { nanostructures } \\
(3 \text { times })\end{array}$ & $\begin{array}{c}808 \mathrm{~nm} ; 1.0 \mathrm{~W} \\
\mathrm{~cm}^{-2} ; 10 \mathrm{~min} \\
(3 \text { times })\end{array}$ & $\mathrm{ZnPP}$ & Tumor eradication & [7] \\
\hline $\begin{array}{l}\text { IR820 and Bortezomib } \\
\text { loaded Cyclosporine } \\
\text { A-functionalized PEG- } \\
\text { coated mesoporous } \\
\text { silica nanoparticles }^{\text {e) }}\end{array}$ & PTT & $\begin{array}{l}\text { PANC-1 tumor } \\
\text { bearing mice }\end{array}$ & i.v. & $\begin{array}{c}\text { N.D. } \\
\text { (4 times) }\end{array}$ & $\begin{array}{c}808 \mathrm{~nm} ; 3.0 \mathrm{~W} \\
\mathrm{~cm}^{-2} ; 5 \mathrm{~min} \\
(4 \text { times })\end{array}$ & Bortezomib & Tumor regression & [137] \\
\hline $\begin{array}{l}\text { IR820 loaded PLGA } \\
\text { nanoparticles }\end{array}$ & PTT & $\begin{array}{l}\text { MDA-MB-231 } \\
\text { tumor bearing } \\
\text { mice }\end{array}$ & i.v. & $\begin{array}{c}0.035 \mu \mathrm{mol} \\
(4 \text { times })\end{array}$ & $\begin{array}{c}810 \mathrm{~nm} ; \\
1.5 \mathrm{~W} \mathrm{~cm}^{-2} ; 5 \mathrm{~min} \\
(4 \text { times })\end{array}$ & - & Tumor regression & [62] \\
\hline $\begin{array}{l}\text { IR820 loaded } \\
\text { PEGylated liposomes }{ }^{f)}\end{array}$ & PTT & $\begin{array}{l}\text { C6 tumor bearing } \\
\text { mice }\end{array}$ & i.v. & $\begin{array}{l}10 \mathrm{mg} \mathrm{kg}^{-1} \text { of } \\
\text { nanostructures }\end{array}$ & $\begin{array}{l}808 \mathrm{~nm} ; \\
1.0 \mathrm{~W} \mathrm{~cm}^{-2} \\
15 \mathrm{~min}\end{array}$ & - & Tumor regression & [138] \\
\hline $\begin{array}{l}\text { IR820 and Irinotecan } \\
\text { loaded hollow } \\
\text { mesoporous silica } \\
\text { nanoparticles }\end{array}$ & PTT & $\begin{array}{l}\text { EMT6 tumor } \\
\text { bearing mice }\end{array}$ & $\begin{array}{l}\text { intraperitoneal } \\
\text { (i.p.) }\end{array}$ & $\begin{array}{l}3 \mathrm{mg} \mathrm{kg}^{-1} \\
\text { (4 times) }\end{array}$ & $\begin{array}{c}808 \mathrm{~nm} ; \\
2.0 \mathrm{~W} \mathrm{~cm}^{-2} ; 5 \mathrm{~min} \\
(4 \text { times })\end{array}$ & Irinotecan & Tumor regression & [139] \\
\hline IR820-ELPg) micelles & PTT & $\begin{array}{l}\text { CT-26 tumor } \\
\text { bearing mice }\end{array}$ & i.v. & N.D. & $\begin{array}{c}808 \mathrm{~nm} ; \\
1.5 \mathrm{~W} \mathrm{~cm}^{-2} ; 8 \mathrm{~min}\end{array}$ & - & $\begin{array}{l}\text { Tumor growth } \\
\text { reduction }\end{array}$ & [31] \\
\hline $\begin{array}{l}\text { IR820 loaded TPP-tar- } \\
\text { geted PEGylated GO } \\
\text { incorporating CPG }\end{array}$ & $\mathrm{PTT} / \mathrm{PDT}$ & $\begin{array}{l}\text { EMT6 tumor } \\
\text { bearing mice }\end{array}$ & i.t. & $20 \mu \mathrm{g}$ & $\begin{array}{c}808 \mathrm{~nm} ; \\
0.5 \mathrm{~W} \mathrm{~cm}^{-2} ; 5 \mathrm{~min}\end{array}$ & $\begin{array}{l}\mathrm{CpG} \\
\mathrm{GO}\end{array}$ & $\begin{array}{l}\text { Tumor growth } \\
\text { reduction }\end{array}$ & [140] \\
\hline $\begin{array}{l}\text { IR820-PTX } \\
\text { nanoparticles }\end{array}$ & PTT & $\begin{array}{l}4 \mathrm{~T} 1 \text { tumor bearing } \\
\text { mice }\end{array}$ & i.v. & $\begin{array}{c}4.2 \mathrm{mg} \mathrm{kg}^{-1} \text { of } \\
\text { nanostructures } \\
\text { (every } 3 \text { days) }\end{array}$ & $\begin{array}{c}660 \mathrm{~nm} ; \\
1.0 \mathrm{~W} \mathrm{~cm}^{-2} ; 5 \mathrm{~min} \\
\text { (every } 3 \text { days) }\end{array}$ & PTX & $\begin{array}{l}\text { Tumor growth } \\
\text { reduction }\end{array}$ & {$[61]$} \\
\hline $\begin{array}{l}\text { Ce6 loaded IR820- } \\
\text { TPGS micelles }\end{array}$ & $\mathrm{PTT} / \mathrm{PDT}$ & $\begin{array}{l}\text { B16 tumor bearing } \\
\text { mice }\end{array}$ & i.v. & $\begin{array}{c}8 \mathrm{mg} \mathrm{kg}^{-1} \\
\text { (every } 3 \text { days) }\end{array}$ & $\begin{array}{c}660 \mathrm{~nm} ; \\
1.0 \mathrm{~W} \mathrm{~cm}^{-2} ; 5 \mathrm{~min} \\
\text { (every } 3 \text { days) }\end{array}$ & $\mathrm{Ce} 6$ & $\begin{array}{l}\text { Tumor growth } \\
\text { reduction }\end{array}$ & [59] \\
\hline
\end{tabular}

a) Dose of heptamethine cyanine (unless stated otherwise); b) formulated with DSPE-PEG, DPPC and cholesterol; c) formulated with mPEG-PCL and PCL-PEI-PEG-(Lyp-1); d) zinc protoporphyrin; e) coated with DPPC, CHO, DSPE-PEG, and DSPE-PEG-(Cyclosporine A); f) formulated with DSPE-PEG, DPPC, DSPC; g)elastin like polypeptide; h) coated with DSPE-PEG-TPP and DSPE-PEG-(cytosine-phosphate-guanine oligodeoxynucleotides) (CPG).

by the high molar extinction coefficient and singlet oxygen quantum yield of IR780. In several reports, IR780 based nanomaterials mediated tumors eradication upon NIR laser irradiation, thereby demonstrating a great potential for cancer PTT/PDT. Furthermore, these nanostructures also displayed the capacity to detect tumors by NIR fluorescence imaging and PAI. On the other hand, nanostructures incorporating IR808, IR820, IR825, and Cypate have not been as extensively explored for cancer phototheragnostic. In the case of IR808, IR825 and Cypate, such could be related to the fact that these dyes are not yet commercially available from the most popular chemical suppliers. Still, the studies reported so far suggest their good potential for cancer PTT/PDT and imaging, as evidenced by the ability of some formulations to photo-ablate tumors.

Regarding nanomaterials incorporating IR775, IR797, and IR806, the information available in the literature on their applicability for in vivo cancer phototheragnostic makes it too preliminary to conclude about their potential. In the case of IR783 and IRDye $800 \mathrm{CW}$ based nanomaterials, only studies 
Table 7. In vivo therapeutic performance of IR 825 based nanostructures.

\begin{tabular}{|c|c|c|c|c|c|c|c|c|}
\hline $\begin{array}{l}\text { IR825 based } \\
\text { nanostructures }\end{array}$ & $\begin{array}{l}\text { Phototherapy } \\
\text { modality }\end{array}$ & Tumor model & $\begin{array}{l}\text { Administration } \\
\text { route }\end{array}$ & Dose $^{a)}$ & Laser parameters & $\begin{array}{l}\text { Other therapeutic } \\
\text { molecules }\end{array}$ & $\begin{array}{c}\text { Therapeutic } \\
\text { effect }\end{array}$ & Ref. \\
\hline HSA-IR825 nanoparticles & PTT & $\begin{array}{l}4 \mathrm{~T} 1 \text { tumor bearing } \\
\text { mice }\end{array}$ & i.v. & $26 \mu g$ & $\begin{array}{c}808 \mathrm{~nm} ; 0.8 \mathrm{~W} \mathrm{~cm}{ }^{-2} \\
10 \mathrm{~min}\end{array}$ & - & $\begin{array}{c}\text { Tumor } \\
\text { eradication }\end{array}$ & [141] \\
\hline $\begin{array}{l}\text { PEG-PDA coated } \\
\text { Mn-IR825 nanoparticles }\end{array}$ & PTT & $\begin{array}{l}4 \mathrm{~T} 1 \text { tumor bearing } \\
\text { mice }\end{array}$ & i.v. & $100 \mu \mathrm{g}$ & $\begin{array}{c}808 \mathrm{~nm} ; 0.6 \mathrm{~W} \mathrm{~cm}{ }^{-2} \\
5 \mathrm{~min}\end{array}$ & PDA & $\begin{array}{c}\text { Tumor } \\
\text { eradication }\end{array}$ & [142] \\
\hline $\begin{array}{l}\text { IR825 loaded PEG-PMAO } \\
\text { micelles }\end{array}$ & PTT & $\begin{array}{l}4 \mathrm{~T} 1 \text { tumor bearing } \\
\text { mice }\end{array}$ & i.v. & $\begin{array}{c}200 \mu \mathrm{g} \text { of } \\
\text { nanostructures }\end{array}$ & $\begin{array}{c}808 \mathrm{~nm} ; 0.5 \mathrm{~W} \mathrm{~cm}{ }^{-2} \\
5 \mathrm{~min}\end{array}$ & - & $\begin{array}{c}\text { Tumor } \\
\text { eradication }\end{array}$ & [39] \\
\hline $\begin{array}{l}\text { IR825 and IONPs }{ }^{\mathrm{C}} \text { ) } \\
\text { loaded PEG-PAA-PAH } \\
\text { nanoparticles }\end{array}$ & PTT & $\begin{array}{l}4 \mathrm{~T} 1 \text { tumor bearing } \\
\text { mice }\end{array}$ & i.v. & $\begin{array}{c}200 \mu \mathrm{g} \text { of } \\
\text { nanostructures }\end{array}$ & $\begin{array}{c}915 \mathrm{~nm} ; 0.7 \mathrm{~W} \mathrm{~cm}{ }^{-2} \\
5 \mathrm{~min}\end{array}$ & IONPS & $\begin{array}{c}\text { Tumor } \\
\text { eradication }\end{array}$ & [27] \\
\hline $\begin{array}{l}\text { dc-IR825 and 17AAG } \\
\text { loaded HSA nanoparticles }\end{array}$ & PTT/PDT & $\begin{array}{l}4 \mathrm{~T} 1 \text { tumor bearing } \\
\text { mice }\end{array}$ & i.v. & $1 \mathrm{mg} \mathrm{kg}^{-1}$ & $\begin{array}{c}808 \mathrm{~nm} ; 0.3 \mathrm{~W} \mathrm{~cm}^{-2} \\
10 \mathrm{~min}\end{array}$ & 17AAG & $\begin{array}{c}\text { Tumor } \\
\text { eradication }\end{array}$ & {$[64]$} \\
\hline $\begin{array}{l}\text { dc-IR825 loaded TPGS } \\
\text { micelles }\end{array}$ & $\mathrm{PTT} / \mathrm{PDT}$ & $\begin{array}{l}\text { U14 tumor bearing } \\
\text { mice }\end{array}$ & i.v. & $3 \mathrm{mg} \mathrm{kg}^{-1}$ & $\begin{array}{c}808 \mathrm{~nm} ; 0.3 \mathrm{~W} \mathrm{~cm}^{-2} \\
10 \mathrm{~min}\end{array}$ & TPGS & $\begin{array}{c}\text { Tumor } \\
\text { eradication }\end{array}$ & {$[65]$} \\
\hline $\begin{array}{l}\text { mPEG- } b-P L D^{\mathrm{e})}-\mathrm{IR} 825^{\mathrm{b}} \text { ) } \\
\text { conjugate micelles }\end{array}$ & PTT & $\begin{array}{l}\text { U14 tumor bearing } \\
\text { mice }\end{array}$ & i.v. & $\begin{array}{l}10 \mathrm{mg} \mathrm{kg}^{-1} \text { of } \\
\text { nanostructures }\end{array}$ & $\begin{array}{c}808 \mathrm{~nm} ; 1.0 \mathrm{~W} \mathrm{~cm}{ }^{-2} \\
10 \mathrm{~min}\end{array}$ & - & $\begin{array}{c}\text { Tumor } \\
\text { eradication }\end{array}$ & {$[46]$} \\
\hline $\begin{array}{l}\text { me-IR825 loaded Pluronic } \\
\text { F-127 based nanoparticles }\end{array}$ & PTT & $\begin{array}{l}\text { U14 tumor bearing } \\
\text { mice }\end{array}$ & i.v. & $\begin{array}{l}300 \mathrm{mg} \mathrm{kg}^{-1} \text { of } \\
\text { nanostructures }\end{array}$ & $\begin{array}{c}808 \mathrm{~nm} ; 1.0 \mathrm{~W} \mathrm{~cm}^{-2} \\
10 \mathrm{~min}\end{array}$ & - & $\begin{array}{c}\text { Tumor } \\
\text { eradication }\end{array}$ & {$[66]$} \\
\hline $\begin{array}{l}\text { PFOB loaded HA-IR825 } \\
\text { nanoparticles }\end{array}$ & PTT & $\begin{array}{l}\text { HT- } 29 \text { tumor } \\
\text { bearing mice }\end{array}$ & i.v. & $\begin{array}{c}500 \mu \mathrm{g} \text { of } \\
\text { nanostructures }\end{array}$ & $\begin{array}{c}808 \mathrm{~nm} ; 1.5 \mathrm{~W} \mathrm{~cm}^{-2} \\
10 \mathrm{~min}\end{array}$ & PFOB & $\begin{array}{l}\text { Tumor } \\
\text { regression }\end{array}$ & [125] \\
\hline $\begin{array}{l}\text { IR825 and CA4 }{ }^{f} \text { loaded } \\
\text { siHSP70g)/PEI-PLA } \\
\text { micelles }\end{array}$ & PTT & $\begin{array}{l}\text { MDA-MB-231 } \\
\text { tumor bearing mice }\end{array}$ & i.v. & $5 \mathrm{mg} \mathrm{kg}^{-1}$ of CA4 & $\begin{array}{c}808 \mathrm{~nm} ; 0.5 \mathrm{~W} \mathrm{~cm}^{-2} \\
5 \mathrm{~min}\end{array}$ & $\begin{array}{c}\text { CA4 } \\
\text { siHSP70 }\end{array}$ & $\begin{array}{l}\text { Tumor } \\
\text { regression }\end{array}$ & [123] \\
\hline $\begin{array}{l}\text { IR825 loaded carbonized } \\
\text { cross-linked PEG-g- } \\
\text { poly(sulfobetaine methac- } \\
\text { rylate) nanoparticles }\end{array}$ & PTT & $\begin{array}{l}\text { MDA-MB-231 } \\
\text { tumor bearing mice }\end{array}$ & i.v. & $\begin{array}{l}10 \mathrm{mg} \mathrm{kg}^{-1} \text { of } \\
\text { nanostructures }\end{array}$ & $\begin{array}{c}808 \mathrm{~nm} ; 2.0 \mathrm{~W} \mathrm{~cm}{ }^{-2} \\
5 \mathrm{~min}\end{array}$ & - & $\begin{array}{l}\text { Tumor } \\
\text { regression }\end{array}$ & [143] \\
\hline $\begin{array}{l}\text { IR825 loaded PEG-g- } \\
\text { (formyl benzoic acid/ } \\
\text { cysteamine/bromoethyl } \\
\text { amine)-conjugated } \\
\text { poly(DMA }{ }^{\text {h)-co-HEMA }} \text { () } \\
\text { nanoparticles }\end{array}$ & PTT & $\begin{array}{l}\text { MDA-MB-231 } \\
\text { tumor bearing mice }\end{array}$ & $\begin{array}{l}\text { subcutaneous } \\
\text { (s.c.) }\end{array}$ & $\begin{array}{l}10 \mathrm{mg} \mathrm{kg}^{-1} \text { of } \\
\text { nanostructures }\end{array}$ & $\begin{array}{c}808 \mathrm{~nm} ; 2.0 \mathrm{~W} \mathrm{~cm}-2 \\
5 \mathrm{~min}\end{array}$ & - & $\begin{array}{l}\text { Tumor } \\
\text { regression }\end{array}$ & [144] \\
\hline $\begin{array}{l}\text { IR825 and DOX loaded } \\
\text { PEG-PAA-PEI aggregates }\end{array}$ & PTT & $\begin{array}{l}4 \mathrm{~T} 1 \text { tumor bearing } \\
\text { mice }\end{array}$ & i.v. & $13 \mathrm{mg} \mathrm{kg}^{-1}$ & $\begin{array}{c}915 \mathrm{~nm} ; 0.35 \mathrm{~W} \mathrm{~cm}^{-2} ; \\
20 \mathrm{~min}\end{array}$ & DOX & $\begin{array}{l}\text { Tumor } \\
\text { regression }\end{array}$ & [124] \\
\hline $\begin{array}{l}\text { PEG-IR825i) and HA-PDA } \\
\text { anchored } \mathrm{rGO}^{\mathrm{k})}\end{array}$ & PTT & $\begin{array}{l}\text { MDA-MB-231 } \\
\text { tumor bearing mice }\end{array}$ & i.v. & $\begin{array}{l}30 \mathrm{mg} \mathrm{kg}^{-1} \text { of } \\
\text { nanostructures }\end{array}$ & $\begin{array}{c}808 \mathrm{~nm} ; 2.0 \mathrm{~W} \mathrm{~cm}{ }^{-2} \\
5 \mathrm{~min}\end{array}$ & $\begin{array}{l}\text { PDA } \\
\text { rGO }\end{array}$ & $\begin{array}{l}\text { Tumor } \\
\text { regression }\end{array}$ & [127] \\
\hline $\begin{array}{l}\text { IR825 loaded TCPP cross- } \\
\text { linked PEGylated micelles') }\end{array}$ & PTT/PDT & $\begin{array}{l}4 \mathrm{~T} 1 \text { tumor bearing } \\
\text { mice }\end{array}$ & i.v. & $100 \mu \mathrm{g}$ & $\begin{array}{c}808 \mathrm{~nm} ; 0.8 \mathrm{~W} \mathrm{~cm}{ }^{-2} \\
5 \mathrm{~min} \\
660 \mathrm{~nm} ; 5 \mathrm{~mW} \mathrm{~cm}{ }^{-2} \\
60 \mathrm{~min}\end{array}$ & TCPP & $\begin{array}{l}\text { Tumor growth } \\
\text { reduction }\end{array}$ & {$[33]$} \\
\hline $\begin{array}{l}\text { IR825 loaded CPT-ada- } \\
\text { mantine } \beta \text {-cyclodextrin-HA } \\
\text { nanoparticles }\end{array}$ & PTT & $\begin{array}{l}\text { U14 tumor bearing } \\
\text { mice }\end{array}$ & i.v. & $\begin{array}{c}200 \mu \mathrm{g} \text { of } \\
\text { nanostructures }\end{array}$ & $\begin{array}{c}808 \mathrm{~nm} ; 0.5 \mathrm{~W} \mathrm{~cm}^{-2} \\
5 \mathrm{~min}\end{array}$ & CPT & $\begin{array}{l}\text { Tumor growth } \\
\text { reduction }\end{array}$ & [145] \\
\hline $\begin{array}{l}\text { IR825 and } \text { RB }^{\mathrm{m})} \text { loaded } \\
\text { BSA-PAA coated UCNPs }\end{array}$ & PTT/PDT & $\begin{array}{l}4 \mathrm{~T} 1 \text { tumor bearing } \\
\text { mice }\end{array}$ & i.t. & $\begin{array}{c}400 \mu \mathrm{g} \text { of } \\
\text { nanostructures }\end{array}$ & $\begin{array}{c}808 \mathrm{~nm} ; 0.5 \mathrm{~W} \mathrm{~cm}^{-2} \\
5 \mathrm{~min} \\
980 \mathrm{~nm} \\
0.4 \mathrm{~W} \mathrm{~cm}^{-2} \\
30 \mathrm{~min}\end{array}$ & $\mathrm{RB}$ & $\begin{array}{l}\text { Tumor growth } \\
\text { reduction }\end{array}$ & [146] \\
\hline
\end{tabular}

a) Dose of heptamethine cyanine (unless stated otherwise); b) IR825 derivative modified with a primary amine; ${ }^{c}$ iron oxide nanoparticles; ${ }^{\text {d) }}$ poly (allylamine hydrochloride); e) poly(L-aspartic acid sodium salt); f) combretastatin A4; g) HSP70 siRNA; h)2-(dimethylamino) ethyl methacrylate; i)2-hydroxyethyl methacrylate; i) IR825 and 2-chloro-3',4'dihydroxyacetophenone quaternized PEG-g-poly(dimethylaminoethyl methacrylate); ${ }^{k}$ reduced graphene oxide; ')formulated with poly[(PEG methyl ether methacrylate)-co(3-aminopropyl methacrylate)]-b-poly (methyl methacrylate); ${ }^{\mathrm{m})}$ rose bengal; ${ }^{\text {n) }}$ upconversion nanoparticles. 
Table 8. In vivo therapeutic performance of other heptamethine cyanine based nanostructures.

\begin{tabular}{|c|c|c|c|c|c|c|c|c|}
\hline $\begin{array}{l}\text { Other hep- } \\
\text { tamethine } \\
\text { cyanine based } \\
\text { nanostructures }\end{array}$ & $\begin{array}{l}\text { Phototherapy } \\
\text { modality }\end{array}$ & Tumor model & $\begin{array}{l}\text { Administration } \\
\text { route }\end{array}$ & Dose $^{a)}$ & Laser parameters & $\begin{array}{l}\text { Other therapeutic } \\
\text { molecules }\end{array}$ & Therapeutic effect & Ref. \\
\hline $\begin{array}{l}\text { IR797 loaded PEG- } \\
\text { PMAO micelles }\end{array}$ & PTT & $\begin{array}{l}\text { HeLa tumor } \\
\text { bearing mice }\end{array}$ & i.t. & $1.05 \mu \mathrm{mol}$ & $\begin{array}{c}808 \mathrm{~nm} ; 1.0 \mathrm{~W} \\
\mathrm{~cm}^{-2} ; 5 \mathrm{~min}\end{array}$ & - & Tumor eradication & [67] \\
\hline $\begin{array}{l}\text { PEGylated IR806 } \\
\text { coated IONPs } \\
\text { micelles }^{\text {b) }}\end{array}$ & PTT & $\begin{array}{l}\text { LLC tumor bearing } \\
\text { mice }\end{array}$ & i.v. & N.D. & $\begin{array}{c}808 \mathrm{~nm} ; 0.25 \mathrm{~W} \\
\mathrm{~cm}^{-2} ; 20 \mathrm{~min}\end{array}$ & IONPs & Tumor regression & {$[147]$} \\
\hline $\begin{array}{l}\text { IR775 loaded } \\
\text { mPEG-PCL } \\
\text { nanoparticles }\end{array}$ & $\mathrm{PTT} / \mathrm{PDT}$ & $\begin{array}{l}\text { A2780/ CDDP } \\
\text { tumor bearing } \\
\text { mice }\end{array}$ & i.v. & $0.75 \mathrm{mg} \mathrm{kg}^{-1}$ & $\begin{array}{l}785 \mathrm{~nm} ; 1.0 \mathrm{~W} \\
\mathrm{~cm}^{-2} ; 20 \mathrm{~min}\end{array}$ & - & $\begin{array}{l}\text { Tumor growth } \\
\text { reduction }\end{array}$ & [10] \\
\hline $\begin{array}{l}\text { IR806-PEG-DSPE } \\
\text { coated } \mathrm{MnFe}_{2} \mathrm{O}_{4} \\
\text { nanoparticles }\end{array}$ & $\mathrm{PTT} / \mathrm{PDT}$ & $\begin{array}{l}\mathrm{H} 22 \text { tumor } \\
\text { bearing mice }\end{array}$ & i.v. & $0.92 \mathrm{mg} \mathrm{kg}^{-1}$ & $\begin{array}{c}808 \mathrm{~nm} ; \\
1.0 \mathrm{~W} \mathrm{~cm}^{-2} ; 5 \mathrm{~min}\end{array}$ & $\begin{array}{c}\mathrm{MnFe}_{2} \mathrm{O}_{4} \\
\text { nanoparticles }\end{array}$ & $\begin{array}{c}\text { Tumor growth } \\
\text { reduction }\end{array}$ & [68] \\
\hline
\end{tabular}

${ }^{a)}$ Dose of heptamethine cyanine (unless stated otherwise); b) prepared by functionalizing IR808 coated IONPs with an mPEG-PCL-(NH ${ }_{2}$-terminated dendritic polyamidoamine) (PAMAM)-based amphiphile.

demonstrating their applicability for in vivo tumor imaging have been reported so far. In this way, developing new formulations containing these NIR heptamethine cyanines will be crucial to prove their applicability for cancer phototheragnostic. The same should be performed for FD-1080 since at the present time, nanoformulations containing this prototypic NIR absorbing heptamethine cyanines have not yet been developed.

In general, the therapeutic capacity of the prototypic NIR heptamethine cyanine incorporating nanomaterials could be further improved through the inclusion of other therapeutic agents (e.g., chemotherapeutics, photosensitizers, or photothermal agents) in the nanoformulations. This strategy also enabled combinatorial phototherapies using lower doses and/ or less intense laser irradiations.

Currently, there are several ongoing clinical trials (phase I and II) studying the diagnosis capabilities of antibody-IRDye $800 \mathrm{CW}$ conjugates (e.g., Bevacizumab-IRDye 800CW). However, the clinical translation of phototheragnostics based on nanomaterials incorporating prototypic NIR heptamethine cyanines has not yet been accomplished. Before envisioning the use of heptamethine cyanine incorporating nanomaterials in clinical trials, it is fundamental to determine their long-term toxicity and confirm their theragnostic capacities in large animal models. Furthermore, the practical use of nanomaterials incorporating prototypic NIR heptamethine cyanines for cancer phototheragnostics is strongly circumscribed to superficial cancers (e.g., melanoma, breast cancer) due to the limits imposed by the penetration depth of the NIR radiation. In this context, phototheragnostics in the secondNIR window (1000-1350 nm) can achieve a higher penetration depth (due to reduced light scattering) and higher maximal permissible exposure (due to the lower energy of longer wavelength photons). ${ }^{[73]}$ Among the different heptamethine cyanines, only FD-1080 has optical properties that enable its efficient use in the second-NIR window. To surpass this bottleneck, endoscopes coupled with fiber-type NIR lasers (e.g., $808 \mathrm{~nm}$ ) are promising devices that may enable the use of nanomaterials incorporating prototypic
NIR heptamethine cyanines for the imaging and PTT/PDT of nonsuperficial tumors. ${ }^{[74]}$

Overall, the continuous development of nanomaterials incorporating the prototypic NIR absorbing heptamethine cyanines will cement their phototheragnostic capabilities.

\section{Acknowledgements}

M.M.L., D.d.M.-D., and C.G.A. contributed equally to this work. This work was supported by European Regional Development Fund and FEDER funds through the POCI-COMPETE 2020-Operational Programme Competitiveness and Internationalisation in Axis I-Strengthening research, technological development and innovation (Project $\mathrm{POCl}$ 01-0145-FEDER-007491, CENTRO-01-0145-FEDER-028989, and POCl01-0145-FEDER-031462) and National Funds by FCT-Foundation for Science and Technology (Project UID/Multi/00709/2013). D.d.M.-D. acknowledges CENTRO-01-0145-FEDER-028989 for the funding given on the form of a research contract. C.G.A. and R.L.-S. acknowledge funding from the grant UBI-Santander/Totta and individual Ph.D. fellowships from FCT (SFRH/BD/145386/2019 and SFRH/BD/144922/2019).

\section{Conflict of Interest}

The authors declare no conflict of interest.

\section{Keywords}

cancer, heptamethine cyanines, NIR imaging, photoacoustic imaging, phototherapies

Received: November 21, 2019

Revised: January 16, 2020

Published online:

[1] a) A. Sneider, D. VanDyke, S. Paliwal, P. Rai, Nanotheranostics 2017, 1, 1; b) X. Song, Q. Chen, Z. Liu, Nano Res. 2015, 8, 340; c) P. Zhang, C. Hu, W. Ran, J. Meng, Q. Yin, Y. Li, Theranostics 2016, 6, 948. 
[2] Y. Cai, W. Si, W. Huang, P. Chen, J. Shao, X. Dong, Small 2018, 14, 1704247.

[3] a) C. G. Alves, R. Lima-Sousa, D. de Melo-Diogo, R. O. Louro, I. J. Correia, Int. J. Pharm. (Amsterdam, Neth.) 2018, 542, 164; b) D. de Melo-Diogo, R. Lima-Sousa, C. G. Alves, I. J. Correia, Biomater. Sci. 2019, 7, 3534; c) D. de Melo-Diogo, E. C. Costa, C. G. Alves, R. Lima-Sousa, P. Ferreira, R. O. Louro, I. J. Correia, Eur. J. Pharm. Biopharm. 2018, 131, 162.

[4] a) Y. Chen, L. Li, W. Chen, H. Chen, J. Yin, Chin. Chem. Lett. 2019, 30, 1353; b) D. de Melo-Diogo, C. Pais-Silva, E. C. Costa, R. O. Louro, I. J. Correia, Nanomedicine 2017, 12, 443.

[5] D. de Melo-Diogo, C. Pais-Silva, D. R. Dias, A. F. Moreira, I. J. Correia, Adv. Healthcare Mater. 2017, 6, 1700073.

[6] F. Yan, W. Duan, H. W. Yekuo Li, Y. Zhou, M. Pan, H. Liu, X. Liu, H. Zheng, Theranostics 2016, 6, 2337.

[7] J. Noh, E. Jung, D. Yoo, C. Kang, C. Kim, S. Park, G. Khang, D. Lee, ACS Appl. Mater. Interfaces 2018, 10, 40424.

[8] a) R. Lima-Sousa, D. de Melo-Diogo, C. G. Alves, E. C. Costa, P. Ferreira, R. O. Louro, I. J. Correia, Carbohydr. Polym. 2018, 200, 93; b) A. F. Moreira, D. R. Dias, E. C. Costa, I. J. Correia, Eur. J. Pharm. Sci. 2017, 104, 42; c) Y.-W. Jiang, G. Gao, P. Hu, J.-B. Liu, Y. Guo, X. Zhang, X.-W. Yu, F.-G. Wu, X. Lu, Nanoscale 2020, 12, 210; d) Y.-W. Bao, X.-W. Hua, X. Chen, F.-G. Wu, Biomaterials 2018, 183, 30; e) G. Gao, Y.-W. Jiang, H.-R. Jia, W. Sun, Y. Guo, X.-W. Yu, X. Liu, F.-G. Wu, Biomaterials 2019, 223, 119443; f) W. Sun, X. Zhang, H. R. Jia, Y. X. Zhu, Y. Guo, G. Gao, Y. H. Li, F. G. Wu, Small 2019, 15, 1804575.

[9] X. Chen, X. Zhang, Y. Guo, Y. X. Zhu, X. Liu, Z. Chen, F. G. Wu, Adv. Funct. Mater. 2019, 29, 1807772.

[10] T. Duong, X. Li, B. Yang, C. Schumann, H. A. Albarqi, O. Taratula, O. Taratula, Nanomedicine (N. Y., NY, U. S.) 2017, 13, 955.

[11] J. Weber, P. C. Beard, S. E. Bohndiek, Nat. Methods 2016, 13, 639.

[12] L. Wu, S. Fang, S. Shi, J. Deng, B. Liu, L. Cai, Biomacromolecules 2013, 14, 3027.

[13] C. Shi, J. B. Wu, D. Pan, J. Biomed. Opt. 2016, 21, 1.

[14] E.-H. Lee, S.-J. Lim, M.-K. Lee, Carbohydr. Polym. 2019, 224, 115143.

[15] S. Zhu, R. Tian, A. L. Antaris, X. Chen, H. Dai, Adv. Mater. 2019, 31, 1900321.

[16] a) Z. Sheng, D. Hu, M. Xue, M. He, P. Gong, L. Cai, Nano-Micro Lett. 2013, 5, 145; b) H. Wang, X. Li, B. W.-C. Tse, H. Yang, C. A. Thorling, Y. Liu, M. Touraud, J. B. Chouane, X. Liu, M. S. Roberts, Theranostics 2018, 8, 1227; c) A. Raza, U. Hayat, T. Rasheed, M. Bilal, H. M. Iqbal, J. Mater. Res. Technol. 2019, 8, 1497.

[17] a) U. Bazylińska, A. Lewińska, Ł. Lamch, K. A. Wilk, Colloids Surf., A 2014, 442, 42; b) K. Kiyose, S. Aizawa, E. Sasaki, H. Kojima, K. Hanaoka, T. Terai, Y. Urano, T. Nagano, Chem. - Eur. J. 2009, 15, 9191.

[18] N. S. James, Y. Chen, P. Joshi, T. Y. Ohulchanskyy, M. Ethirajan, M. Henary, L. Strekowsk, R. K. Pandey, Theranostics 2013, 3, 692.

[19] K. Licha, B. Riefke, V. Ntziachristos, A. Becker, B. Chance, W. Semmler, Photochem. Photobiol. 2000, 72, 392.

[20] T. Jing, L. Fu, L. Liu, L. Yan, Polym. Chem. 2016, 7, 951

[21] S. Luo, Z. Yang, X. Tan, Y. Wang, Y. Zeng, Y. Wang, C. Li, R. Li, C. Shi, ACS Appl. Mater. Interfaces 2016, 8, 17176.

[22] N. Zhao, C. Zhang, Y. Zhao, B. Bai, J. An, H. Zhang, J. B. Wu, C. Shi, Oncotarget 2016, 7, 57277.

[23] E. Zhang, S. Luo, X. Tan, C. Shi, Biomaterials 2014, 35, 771.

[24] X. Yang, C. Shi, R. Tong, W. Qian, H. E. Zhau, R. Wang, G. Zhu, J. Cheng, V. W. Yang, T. Cheng, Clin. Cancer Res. 2010, 16, 2833.

[25] X. Tan, S. Luo, D. Wang, Y. Su, T. Cheng, C. Shi, Biomaterials 2012, 33, 2230.

[26] A. Yuan, X. Qiu, X. Tang, W. Liu, J. Wu, Y. Hu, Biomaterials 2015, $51,184$.
[27] X. Song, H. Gong, T. Liu, L. Cheng, C. Wang, X. Sun, C. Liang, Z. Liu, Small 2014, 10, 4362.

[28] M. V. Marshall, D. Draney, E. M. Sevick-Muraca, D. M. Olive, Mol. Imaging Biol. 2010, 12, 583.

[29] Y. Liu, P. Bhattarai, Z. Dai, X. Chen, Chem. Soc. Rev. 2019, 48, 2053.

[30] S. Li, Z. Sun, G. Deng, X. Meng, W. Li, D. Ni, J. Zhang, P. Gong, L. Cai, Biomater. Sci. 2017, 5, 1122.

[31] K. Huang, M. Gao, L. Fan, Y. Lai, H. Fan, Z. Hua, Biomater. Sci. 2018, 6, 2925.

[32] R. Ge, J. Cao, J. Chi, S. Han, Y. Liang, L. Xu, M. Liang, Y. Sun, Int. J. Nanomed. 2019, 14, 4931.

[33] X. Liu, G. Yang, L. Zhang, Z. Liu, Z. Cheng, X. Zhu, Nanoscale 2016, 8, 15323.

[34] C. G. Alves, D. de Melo-Diogo, R. Lima-Sousa, E. C. Costa, I. J. Correia, Eur. J. Pharm. Biopharm. 2019, 137, 86.

[35] C. Pais-Silva, D. de Melo-Diogo, I. J. Correia, Eur. J. Pharm. Biopharm. 2017, 113, 108.

[36] H.-R. Jia, Y.-X. Zhu, X. Liu, G.-Y. Pan, G. Gao, W. Sun, X. Zhang, Y.-W. Jiang, F.-G. Wu, ACS Nano 2019, 13, 11781.

[37] L. Zhou, Y. Wu, X. Meng, S. Li, J. Zhang, P. Gong, P. Zhang, T. Jiang, G. Deng, W. Li, Small 2018, 14, 1801008.

[38] M. Liu, P. Zhang, L. Deng, D. Guo, M. Tan, J. Huang, Y. Luo, Y. Cao, Z. Wang, Biomater. Sci. 2019, 7, 1132.

[39] L. Cheng, W. He, H. Gong, C. Wang, Q. Chen, Z. Cheng, Z. Liu, Adv. Funct. Mater. 2013, 23, 5893.

[40] Y. Zhang, C. Y. Ang, M. Li, S. Y. Tan, Q. Qu, Y. Zhao, ACS Appl. Mater. Interfaces 2016, 8, 6869.

[41] B. Xia, B. Wang, Z. Chen, Q. Zhang, J. Shi, Adv. Mater. Interfaces 2016, 3, 1500715 .

[42] a) A. Fernandez-Fernandez, R. Manchanda, D. A. Carvajal, T. Lei, A. J. McGoron, in Proc. SPIE 8596, Reporters, Markers, Dyes, Nanoparticles, and Molecular Probes for Biomedical Applications V, SPIE, Bellingham, WA 2013, 859605; b) Y. Matsumoto, J. W. Nichols, K. Toh, T. Nomoto, H. Cabral, Y. Miura, R. J. Christie, N. Yamada, T. Ogura, M. R. Kano, Y. Matsumura, N. Nishiyama, T. Yamasoba, Y. H. Bae, K. Kataoka, Nat. Nanotechnol. 2016, 11, 533.

[43] Y. Tian, R. Guo, Y. Wang, W. Yang, Adv. Healthcare Mater. 2016, 5, 3099.

[44] H. Chen, B. Li, J. Qiu, J. Li, J. Jin, S. Dai, Y. Ma, Y. Gu, Nanoscale 2013, 5, 12409.

[45] a) D. de Melo-Diogo, R. Lima-Sousa, C. G. Alves, E. C. Costa, R. O. Louro, I. J. Correia, Colloids Surf., B 2018, 171, 260; b) A. F. Moreira, D. R. Dias, I. J. Correia, Microporous Mesoporous Mater. 2016, 236, 141; c) S. Wilhelm, A. J. Tavares, Q. Dai, S. Ohta, J. Audet, H. F. Dvorak, W. C. W. Chan, Nat. Rev. Mater. 2016, 1, 16014; d) M. F. Attia, N. Anton, J. Wallyn, Z. Omran, T. F. Vandamme, J. Pharm. Pharmacol. 2019, 71, 1185; e) C. F. Rodrigues, T. A. Jacinto, A. F. Moreira, E. C. Costa, S. P. Miguel, I. J. Correia, Nano Res. 2019, 12, 719.

[46] G.-Y. Pan, H.-R. Jia, Y.-X. Zhu, F.-G. Wu, Nanoscale 2018, 10, 2115.

[47] J. Song, N. Zhang, L. Zhang, H. Yi, Y. Liu, Y. Li, X. Li, M. Wu, L. Hao, Z. Yang, Z. Wang, Int. J. Nanomed. 2019, 14, 2757.

[48] S. Xiang, K. Zhang, G. Yang, D. Gao, C. Zeng, M. He, Nanoscale Res. Lett. 2019, 14, 211

[49] Q. Yang, Y. Xiao, Y. Yin, G. Li, J. Peng, Mol. Pharmaceutics 2019, $16,7$.

[50] X. Wang, J. Yan, D. Pan, R. Yang, L. Wang, Y. Xu, J. Sheng, Y. Yue, Q. Huang, Y. Wang, R. Wang, M. Yang, Adv. Healthcare Mater. 2018, 7, 1701505.

[51] S. Wang, F. Guo, Y. Ji, M. Yu, J. Wang, N. Li, Mol. Pharmaceutics 2018, 15, 3318.

[52] X. Yang, H. Li, C. Qian, Y. Guo, C. Li, F. Gao, Y. Yang, K. Wang, D. Oupicky, M. Sun, Nanomedicine (N. Y., NY, U. S.) 2018, 14, 2283. 
[53] Z. Yang, R. Cheng, C. Zhao, N. Sun, H. Luo, Y. Chen, Z. Liu, X. Li, J. Liu, Z. Tian, Theranostics 2018, 8, 4097.

[54] Y. Wang, T. Yang, H. Ke, A. Zhu, Y. Wang, J. Wang, J. Shen, G. Liu, C. Chen, Y. Zhao, Adv. Mater. 2015, 27, 3874.

[55] Y. Li, Y. Deng, X. Tian, H. Ke, M. Guo, A. Zhu, T. Yang, Z. Guo, Z. Ge, X. Yang, ACS Nano 2015, 9, 9626.

[56] X. An, A. Zhu, H. Luo, H. Ke, H. Chen, Y. Zhao, ACS Nano 2016, 10, 5947.

[57] W. Miao, H. Kim, V. Gujrati, J. Y. Kim, H. Jon, Y. Lee, M. Choi, J. Kim, S. Lee, D. Y. Lee, Theranostics 2016, 6, 2367.

[58] H. Yu, Z. Cui, P. Yu, C. Guo, B. Feng, T. Jiang, S. Wang, Q. Yin, D. Zhong, X. Yang, Adv. Funct. Mater. 2015, 25, 2489.

[59] X. Hu, H. Tian, W. Jiang, A. Song, Z. Li, Y. Luan, Small 2018, 14, 1802994.

[60] P. Huang, P. Rong, A. Jin, X. Yan, M. G. Zhang, J. Lin, H. Hu, Z. Wang, X. Yue, W. Li, Adv. Mater. 2014, 26, 6401.

[61] D. Zhang, J. Zhang, Q. Li, H. Tian, N. Zhang, Z. Li, Y. Luan, ACS Appl. Mater. Interfaces 2018, 10, 30092.

[62] D. M. Valcourt, M. N. Dang, E. S. Day, J. Biomed. Mater. Res., Part A 2019, 107, 1702

[63] W. Li, J. Peng, L. Tan, J. Wu, K. Shi, Y. Qu, X. Wei, Z. Qian, Biomaterials 2016, 106, 119.

[64] G. Gao, Y. W. Jiang, W. Sun, Y. Guo, H. R. Jia, X. W. Yu, G. Y. Pan, F. G. Wu, Small 2019, 15, 1900501

[65] Y.-X. Zhu, H.-R. Jia, G. Gao, G.-Y. Pan, Y.-W. Jiang, P. Li, N. Zhou, C. Li, C. She, N. W. Ulrich, Biomaterials 2019, 232, 119668.

[66] G.-Y. Pan, H.-R. Jia, Y.-X. Zhu, W. Sun, X.-T. Cheng, F.-G. Wu, ACS Appl. Nano Mater. 2018, 1, 2885.

[67] Y. F. Xiao, F. F. An, J. X. Chen, J. Yu, W. W. Tao, Z. Yu, R. Ting, C. S. Lee, X. H. Zhang, Small 2019, 15, 1903121.

[68] K. Deng, Y. Chen, C. Li, X. Deng, Z. Hou, Z. Cheng, Y. Han, B. Xing, J. Lin, J. Mater. Chem. B 2017, 5, 1803.

[69] B. Zhang, H. Wang, S. Shen, X. She, W. Shi, J. Chen, Q. Zhang, Y. Hu, Z. Pang, X. Jiang, Biomaterials 2016, 79, 46.

[70] J. Feng, S. Li, H.-J. Fan, Y. Lin, Y. Lu, Colloids Surf., B 2019, 178, 146.

[71] L. Li, T. L. M. ten Hagen, M. Bolkestein, A. Gasselhuber, J. Yatvin, G. C. van Rhoon, A. M. M. Eggermont, D. Haemmerich, G. A. Koning, J. Controlled Release 2013, 167, 130.

[72] B. B. Azad, S. R. Banerjee, M. Pullambhatla, S. Lacerda, C. A. Foss, Y. Wang, R. Ivkov, M. G. Pomper, Nanoscale 2015, 7, 4432.

[73] X. Ge, Q. Fu, L. Bai, B. Chen, R. Wang, S. Gao, J. Song, New J. Chem. 2019, 43, 8835 .

[74] E. Gournaris, W. Park, S. Cho, D. J. Bentrem, A. C. Larson, D.-H. Kim, ACS Appl. Mater. Interfaces 2019, 11, 24.

[75] B. Li, L. Lu, M. Zhao, Z. Lei, F. Zhang, Angew. Chem., Int. Ed. 2018, 57, 7483 .

[76] G. Deng, S. Li, Z. Sun, W. Li, L. Zhou, J. Zhang, P. Gong, L. Cai, Theranostics 2018, 8, 4116 .

[77] a) Q. Li, J. Tan, B.-X. Peng, Molecules 1997, 2, 91; b) L. Zhang, D. Wang, K. Yang, D. Sheng, B. Tan, Z. Wang, H. Ran, H. Yi, Y. Zhong, H. Lin, Y. Chen, Adv. Sci. (Weinheim, Ger.) 2018, 5, 1800049 .

[78] K. Mitra, C. E. Lyons, M. C. Hartman, Angew. Chem., Int. Ed. 2018, 57, 10263.

[79] W. Zou, C. Visser, J. A. Maduro, M. S. Pshenichnikov, J. C. Hummelen, Nat. Photonics 2012, 6, 560.

[80] S. Luo, X. Tan, Q. Qi, Q. Guo, X. Ran, L. Zhang, E. Zhang, Y. Liang, L. Weng, H. Zheng, Biomaterials 2013, 34, 2244

[81] M. J. Duffy, O. Planas, A. Faust, T. Vogl, S. Hermann, M. Schäfers, S. Nonell, C. A. Strassert, Photoacoustics 2018, 9, 49.

[82] Y. Zhang, L. He, J. Wu, K. Wang, J. Wang, W. Dai, A. Yuan, J. Wu, Y. Hu, Biomaterials 2016, 107, 23.

[83] X. Li, X. Wang, C. Zhao, L. Shao, J. Lu, Y. Tong, L. Chen, X. Cui, H. Sun, J. Liu, J. Nanobiotechnol. 2019, 17, 23.
[84] S. Li, S. Zhou, Y. Li, X. Li, J. Zhu, L. Fan, S. Yang, ACS Appl. Mater. Interfaces 2017, 9, 22332

[85] H. Li, X. Yang, Z. Zhou, K. Wang, C. Li, H. Qiao, D. Oupicky, M. Sun, J. Controlled Release 2017, 261, 126.

[86] H. Li, K. Wang, X. Yang, Y. Zhou, Q. Ping, D. Oupicky, M. Sun, Acta Biomater. 2017, 53, 399.

[87] Y. Shen, W. Lv, H. Yang, W. Cai, P. Zhao, L. Zhang, J. Zhang, L. Yuan, Y. Duan, Cancer Lett. (N. Y., NY, U. S.) 2019, 455, 14.

[88] Y. Deng, F. Käfer, T. Chen, Q. Jin, J. Ji, S. Agarwal, Small 2018, 14, 1802420.

[89] S. Ma, J. Zhou, Y. Zhang, B. Yang, Y. He, C. Tian, X. Xu, Z. Gu, ACS Appl. Mater. Interfaces 2019, 11, 7731.

[90] S.-Y. Lin, R.-Y. Huang, W.-C. Liao, C.-C. Chuang, C.-W. Chang, Nanotheranostics 2018, 2, 106

[91] H. Lian, J. Wu, Y. Hu, H. Guo, Int. J. Nanomed. 2017, 12, 7777.

[92] F. Guo, M. Yu, J. Wang, F. Tan, N. Li, ACS Appl. Mater. Interfaces 2015, 7, 20556.

[93] Y. Xing, T. Ding, Z. Wang, L. Wang, H. Guan, J. Tang, D. Mo, J. Zhang, ACS Appl. Mater. Interfaces 2019, 11, 13945.

[94] X. Qiu, L. Xu, Y. Zhang, A. Yuan, K. Wang, X. Zhao, J. Wu, H. Guo, Y. Hu, Mol. Pharmaceutics 2016, 13, 829.

[95] J. Tian, B. Huang, H. Li, H. Cao, W. Zhang, Biomacromolecules 2019, 20, 6 .

[96] W. He, Y. Jiang, Q. Li, D. Zhang, Z. Li, Y. Luan, Acta Biomater. 2019, 84, 356

[97] K. Wang, Y. Zhang, J. Wang, A. Yuan, M. Sun, J. Wu, Y. Hu, Sci. Rep. 2016, 6, 27421.

[98] C. Zhao, Y. Tong, X. Li, L. Shao, L. Chen, J. Lu, X. Deng, X. Wang, Y. Wu, Small 2018, 14, 1703045.

[99] N. Li, F. Xu, J. Cheng, Y. Zhang, G. Huang, J. Zhu, X. Shen, D. He, J. Biomed. Nanotechnol. 2018, 14, 2162.

[100] Y. Xu, H. Ren, J. Liu, Y. Wang, Z. Meng, Z. He, W. Miao, G. Chen, X. Li, Nanoscale 2019, 11, 5474

[101] H. Li, H. Liu, T. Nie, Y. Chen, Z. Wang, H. Huang, L. Liu, Y. Chen, Biomaterials 2018, 178, 620 .

[102] Y. Tan, Y. Zhu, L. Wen, X. Yang, X. Liu, T. Meng, S. Dai, Y. Ping, H. Yuan, F. Hu, Theranostics 2019, 9, 691

[103] A. Yuan, W. Huan, X. Liu, Z. Zhang, Y. Zhang, J. Wu, Y. Hu, Mol. Pharmaceutics 2016, 14, 242.

[104] G. Chen, K. Wang, Y. Zhou, L. Ding, A. Ullah, Q. Hu, M. Sun, D. Oupický, ACS Appl. Mater. Interfaces 2016, 8, 25087.

[105] K. Wang, G. Chen, Q. Hu, Y. Zhen, H. Li, J. Chen, B. Di, Y. Hu, M. Sun, D. Oupický, Nanomedicine 2017, 12, 1043.

[106] J. Song, L. Zhang, H. Yi, J. Huang, N. Zhang, Y. Zhong, L. Hao, K. Yang, Z. Wang, D. Wang, Nanomedicine (N. Y., NY, U. S.) 2019 20, 102020

[107] A. Samykutty, W. E. Grizzle, B. L. Fouts, M. W. McNally, P. Chuong, A. Thomas, A. Chiba, D. Otali, A. Woloszynska, N. Said, Biomaterials 2018, 182, 114.

[108] S. Li, J. Johnson, A. Peck, Q. Xie, J. Transl. Med. 2017, 15, 18.

[109] H. Han, J. Wang, T. Chen, L. Yin, Q. Jin, J. Ji, J. Colloid Interface Sci. 2017, 507, 217.

[110] A. Ullah, K. Wang, P. Wu, D. Oupicky, M. Sun, Int. J. Nanomed. 2019, 14, 2927.

[111] Y. Lee, S. Lee, S. Jon, Adv. Sci. (Weinheim, Ger.) 2018, 5, 1800017.

[112] Y. Han, Z. Chen, H. Zhao, Z. Zha, W. Ke, Y. Wang, Z. Ge, J. Controlled Release 2018, 284, 15.

[113] H. Luo, Q. Wang, Y. Deng, T. Yang, H. Ke, H. Yang, H. He, Z. Guo, D. Yu, H. Wu, Adv. Funct. Mater. 2017, 27, 1702834.

[114] M. Guo, J. Huang, Y. Deng, H. Shen, Y. Ma, M. Zhang, A. Zhu, Y. Li, H. Hui, Y. Wang, Adv. Funct. Mater. 2015, 25, 59.

[115] M. Guo, H. Mao, Y. Li, A. Zhu, H. He, H. Yang, Y. Wang, X. Tian, C. Ge, Q. Peng, Biomaterials 2014, 35, 4656.

[116] Y. Deng, L. Huang, H. Yang, H. Ke, H. He, Z. Guo, T. Yang, A. Zhu, H. Wu, H. Chen, Small 2017, 13, 1602747. 
[117] H. Yang, H. Mao, Z. Wan, A. Zhu, M. Guo, Y. Li, X. Li, J. Wan, X. Yang, X. Shuai, Biomaterials 2013, 34, 9124.

[118] C.-S. Yeh, C.-H. Su, W.-Y. Ho, C.-C. Huang, J.-C. Chang, Y.-H. Chien, S.-T. Hung, M.-C. Liau, H.-Y. Ho, Biomaterials 2013, 34, 5677.

[119] R. G. Thomas, M. J. Moon, S. P. Surendran, H. J. Park, I.-K. Park, B.-I. Lee, Y. Y. Jeong, Mol. Imaging Biol. 2018, 20, 533.

[120] S. Lee, R. George Thomas, M. Ju Moon, H. Ju Park, I.-K. Park, B.-I. Lee, Y. Yeon Jeong, Sci. Rep. 2017, 7, 2108.

[121] R. P. Johnson, Y. I. Jeong, J. V. John, C. W. Chung, S. H. Choi, S. Y. Song, D. H. Kang, H. Suh, I. Kim, Macromol. Rapid Commun. 2014, 35, 888

[122] H. Han, H. Wang, Y. Chen, Z. Li, Y. Wang, Q. Jin, J. Ji, Nanoscale 2016, 8, 283.

[123] L. Shao, Q. Li, C. Zhao, J. Lu, X. Li, L. Chen, X. Deng, G. Ge, Y. Wu, Biomaterials 2019, 194, 105.

[124] X. Song, R. Zhang, C. Liang, Q. Chen, H. Gong, Z. Liu, Biomaterials 2015, 57, 84 .

[125] X. Liang, L. Fang, X. Li, X. Zhang, F. Wang, Biomaterials 2017, 132, 72.

[126] Z. Yang, J. Song, W. Tang, W. Fan, Y. Dai, Z. Shen, L. Lin, S. Cheng, Y. Liu, G. Niu, Theranostics 2019, 9, 526.

[127] S. H. Kim, J. E. Lee, S. M. Sharker, J. H. Jeong, I. In, S. Y. Park, Biomacromolecules 2015, 16, 3519.

[128] L. Meng, S. Gan, Y. Zhou, Y. Cheng, Y. Ding, X. Tong, J. Wu, Y. Hu, A. Yuan, Biomater. Sci. 2019, 7, 168.

[129] L. Meng, Y. Cheng, S. Gan, Z. Zhang, X. Tong, L. Xu, X. Jiang, Y. Zhu, J. Wu, A. Yuan, Mol. Pharmaceutics 2018, 15, 447.

[130] Y. Zhao, G. Chen, Z. Meng, G. Gong, W. Zhao, K. Wang, T. Liu, Drug Delivery 2019, 26, 717.

[131] Y. Li, Y. Du, X. Liu, Q. Zhang, L. Jing, X. Liang, C. Chi, Z. Dai, J. Tian, Mol. Imaging 2015, 14, 7.

[132] L. Jing, S. Shao, Y. Wang, Y. Yang, X. Yue, Z. Dai, Theranostics 2016, 6,1 .
[133] M.-M. Chen, Y.-Y. Liu, G.-H. Su, F.-F. Song, Y. Liu, Q.-Q. Zhang, Int. J. Nanomed. 2017, 12, 4225.

[134] Y. Wang, Z. Sun, Z. Chen, Y. Wu, Y. Gu, S. Lin, Y. Wang, Anal. Chem. 2019, 91, 3.

[135] L. Sha, Q. Zhao, D. Wang, X. Li, X. Wang, X. Guan, S. Wang, J. Colloid Interface Sci. 2019, 535, 380.

[136] T. H. Tran, H. T. Nguyen, N. Van Le, T. T. P. Tran, J. S. Lee, S. K. Ku, H.-G. Choi, C. S. Yong, J. O. Kim, Int. J. Pharm. (Amsterdam, Neth.) 2017, 528, 692.

[137] R. K. Thapa, H. T. Nguyen, M. Gautam, A. Shrestha, E. S. Lee, S. K. Ku, H.-G. Choi, C. S. Yong, J. O. Kim, Drug Delivery 2017, 24, 1690.

[138] B. Wu, B. Wan, S.-T. Lu, K. Deng, X.-Q. Li, B.-L. Wu, Y.-S. Li, R.-F. Liao, S.-W. Huang, H.-B. Xu, Int. J. Nanomed. 2017, 12, 4467.

[139] T. Li, X. Shen, X. Xie, Z. Chen, S. Li, X. Qin, H. Yang, C. Wu, Y. Liu, Nanomedicine 2018, 13, 595.

[140] C. Wu, L. Wang, Y. Tian, X. Guan, Q. Liu, S. Li, X. Qin, H. Yang, Y. Liu, ACS Appl. Mater. Interfaces 2018, 10, 6942.

[141] Q. Chen, C. Wang, Z. Zhan, W. He, Z. Cheng, Y. Li, Z. Liu, Biomaterials 2014, 35, 8206.

[142] Y. Yang, J. Liu, C. Liang, L. Feng, T. Fu, Z. Dong, Y. Chao, Y. Li, G. Lu, M. Chen, ACS Nano 2016, 10, 2774.

[143] E. B. Kang, J. E. Lee, Z. A. I. Mazrad, I. In, J. H. Jeong, S. Y. Park, Nanoscale 2018, 10, 2512

[144] C. A. Choi, J. E. Lee, Z. A. I. Mazrad, Y. K. Kim, I. In, J. H. Jeong, S. Y. Park, ChemMedChem 2018, 13, 1459.

[145] Y. Zhang, D. Yang, H. Chen, W. Q. Lim, F. S. Z. Phua, G. An, P. Yang, Y. Zhao, Biomaterials 2018, 163, 14.

[146] Q. Chen, C. Wang, L. Cheng, W. He, Z. Cheng, Z. Liu, Biomaterials 2014, 35, 2915.

[147] Y. Chang, X. Li, X. Kong, Y. Li, X. Liu, Y. Zhang, L. Tu, B. Xue, F. Wu, D. Cao, J. Mater. Chem. B 2015, 3, 8321. 